\title{
The Deep Drawing of a Flanged Square Hole in Thin Stainless Steel Sheet
}

\author{
Tsung-Chia Chen ${ }^{1}\left[\right.$, Ching-Min Hsu ${ }^{1}$ and Cheng-Chi Wang ${ }^{2, *(\mathbb{D})}$ \\ 1 Department of Mechanical Engineering, National Chin-Yi University of Technology, Zhongshan Rd., \\ Taiping District, Taichung 411030, Taiwan; ctchen@ncut.edu.tw (T.-C.C.); \\ av80882001@yahoo.com.tw (C.-M.H.) \\ 2 Graduate Institute of Precision Manufacturing, National Chin-Yi University of Technology, Zhongshan Rd., \\ Taiping District, Taichung 411030, Taiwan \\ * Correspondence: wcc@ncut.edu.tw; Tel.: +886-9-2958-5400
}

Citation: Chen, T.-C.; Hsu, C.-M.; Wang, C.-C. The Deep Drawing of a Flanged Square Hole in Thin Stainless Steel Sheet. Metals 2021, 11, 1436. https://doi.org/10.3390/met11091436

Academic Editors: Pavel Krakhmalev and Marta Oliveira

Received: 14 July 2021

Accepted: 9 September 2021

Published: 10 September 2021

Publisher's Note: MDPI stays neutral with regard to jurisdictional claims in published maps and institutional affiliations.

Copyright: (c) 2021 by the authors. Licensee MDPI, Basel, Switzerland. This article is an open access article distributed under the terms and conditions of the Creative Commons Attribution (CC BY) license (https:// creativecommons.org/licenses/by/ $4.0 /)$.

\begin{abstract}
To manufacture metal products of accurate size and shape by deep drawing requires the precise control of a number of variables. The problem of spring-back after the load has to be avoided, and the prevention of cracks in the product requires careful control of the punch load. In this study, where drawing experiments and simulations were carried out on thin sheets of SUS304 stainless steel, the influence of the scale effect on the thin sheets also needed consideration. This was accomplished by the use of an updated Lagrangian formulation and finite element analysis. Material behavior was simulated using a micro-elastoplastic material model, the performance of which was compared with that of models involving conventional materials. The Dynaform LS-DYNA solver was used for simulation analysis, and pre and postprocessing were carried out to obtain material deformation history as well as to determine thickness change, distribution and material stress, and prepare strain distribution maps. Scaling was necessary to account for the effect of the thickness of the sheet and the relationship between punch load and stroke, the distribution of thickness, stress and strain, and the maximum size (d) of the flanged hole and the maximum height of the flange. The simulation results were compared with experimental results to confirm the accuracy of the three-dimensional finite element analysis of the elastoplastic deformation. The results showed that the size of the fillet radius of the hole $(\mathrm{Br})$ had an effect on the punch load, which increased with an increase in Br. However, the minimum thickness of the formed flange decreased with an increase in Br. The maximum principal stress/strain and height of the flange also increased with an increase in $\mathrm{Br}$. The punch fillet radius $\left(R_{p}\right)$ also had an impact on the process. The punch load decreased with the increase in $R_{p}$, while the minimum thickness increased slightly. The average values of the minimum thickness for three models were $0.148,0.0775$, and $0.0374 \mathrm{~mm}$. The forming ratio also had an influence on the process. When the forming limit of the square hole flange was $F L R=0.84$, cracking occurred in the corners of the flange, and wrinkles formed over the undrawn area of the sheet. These findings can serve as a valuable reference for the design of deep drawing processes.
\end{abstract}

Keywords: deep drawing; spring-back; stainless steel; material deformation history

\section{Introduction}

As a response to the growing demand for miniaturization, the production of sheetformed products has experienced substantial growth in recent years. Sheet forming technology can be classified as drawing, stretch-flanging, and bending. During the forming process, defects, such as fractures and excessive local thinning or wrinkling, may arise as a result of insufficient formability or incorrect parameter settings. Such defects may affect the precision and life of the workpiece as well as product yield. They need to be avoided at the mold design stage. The miniaturization of metal forming processes is influenced by the scale effect, and the parameter control differs from that used in general metal forming. For example, surface roughness of the metal and friction during the forming process, as well as 
plastic flow stress and spring-back, are very important. This makes accurate prediction and control of the parameters in micro forming processes very important [1-4].

Sheet metal micro-forming is one of the key processing techniques used in the manufacturing industry and has three basic categories [5]: drawing, stretch-flanging, and bending. In the forming process, sheet metal can fracture, suffer local over-thinning, or wrinkle because of bad formability or the incorrect setting of processing parameters. This has now become an important area of research. Square hole-flanging is a type of sheet metal drawing [6] that can be used for making automobile or aircraft parts, pipe connections, and parts of many ordinary household appliances. In general sheet metal forming, the processing parameters are usually acquired by trial and error, or determined by experts based on experience. However, now that parameters can be determined by simulation, for square hole-flanging, as in this study, for example, the guesswork can be eliminated. This saves time, manpower, and money in die making factories.

In the plastic deformation of sheet metal there are many factors that need consideration, which include the actual properties of the material, the shape of the die, and the friction between the punch, the die, and the sheet metal. The square-hole-flanging procedure discussed in this study starts with the reaming and drawing of a piece of sheet metal with a square hole using a square punch. The metal bends close to the square column of the punch; the square hole expands with the descending punch, and the periphery expands; the metal thins to a forming limit after a certain amount of drawing. The peripheral thickness of the hole is rapidly thinned as necking proceeds, and then it fractures. These square hole flanging steps can all be simulated in advance to avoid such an unfortunate outcome. The sheet metal thickness distribution and the thinned form distribution from a macro to micro relationship between punch load and stroke, as well as the deformation, which can all be pre-simulated, and a stress-strain diagram can be prepared. The advantages of computer numerical simulation are utilized to reduce costs by shortening the development and design period as well as improving product quality and optimizing the design process.

Kawka and Makinouchi [7] proposed degenerated shell elements and combined them in a statically explicit finite element equation to compare distinct integration rules, including complete integration, simplified integration, selective reduced integration, the assumed strain field, and the stable matrix rule. When Leu [8] discussed hole-flanging with the elastic-plastic finite element method, the stress borne by the hole periphery was assumed to be a single circular drawing stress so that the destructive model was simplified into a simple drawing test. Furthermore, an if-statement composed of a stress concentration factor, a work hardening index, and an orthotropic coefficient was deducted from the uniaxial drawing test to judge the hole edge necking of the flange. Takuda and Hatta [9] analyzed sheet metal forming using the rigid-plastic finite element method and utilized ductile fracture criteria for estimating the forming limit of commercial zircon sheet metal in a deep drawing process. The results showed the higher drawability of the zircon sheet and fracture location could be predicted using a combination of finite element analysis and ductile fracture criteria. Kumagai et al. [10] studied the thinning in hole-flanging in an $\mathrm{Al} / \mathrm{Cu}$ alloy sheet where a cone punch with an angle of $45^{\circ}$ was used for a hole-flanging test. The final shape of the flanged hole could be predicted by a comparison of FEM simulation results with experimental results, using the rigid-plastic finite element method. Worswick and Finn [11] simulated the formation of round, square and $\mathrm{Z}$ hole-flanges using the explicit dynamic finite element method and combined the forming limit diagram with the yield criteria of Von Mises, Hill, and Barlat to discuss the sheet metal forming limit. Huang and Chien [12] analyzed the forming limit of cylindrical punch radius in hole-flanging. Numerical analyses showed that the effects of punch contour radius on the forming limit was not obvious but was largely dependent on the punch load. Leu et al. [13] compared the maximal punch load in hole-flanging with various geometric shapes of punch (cone, hemisphere, and cylinder) and the changes in some processing parameters. Their numerical simulation and experimental results showed that the forming load on the cylindrical punch was the highest. The load on the punch increased sharply with punch 
angle in the conical punch, and the friction coefficient increased gradually for the other punches as well. In this present study, a square hole blank was stretched and formed with a square punch in such a way that the blank adhered to the arc corner of the punch and bent to form a square column. The stretch forming behavior of the flange around a square hole is quite complex, and careful simulation and analysis were required to ensure a finished product with accurate size and shape. Dynaform finite element analysis was used to simulate the stretch forming, and experiments were conducted to confirm and analyze the results. This was done specifically to determine whether Dynaform could produce accurate data for the stretch forming process that would be suitable for use in the relevant factory procedures, and to provide a reference for stretch forming parameters and mold design.

\section{Theoretical Analysis}

\subsection{Basic Hypothesis and Evolution of Principle}

Several assumptions have been made with respect to the elasto-plastic deformation properties of the blanks used in this study.

1. The material was assumed to be homogeneous.

2. The material was assumed to be planar anisotropic.

3. The elasticity of the material satisfied Hooke's Law.

4. A die was considered to be a rigid body.

5. The effect of residual stress on material formation was ignored.

6. The effect of temperature on material formation was ignored.

A governing equation suitable for various metal forming processes was deduced with the stress-stress rate relationship in metal material deformation, using an updated Lagrangian formulation (ULF) in finite deformation and material composition. The Jaumann Cauchy stress differential rate was used in the constitutive equation, and in updating the principle of virtual work formed by the Lagrangian, the volume function could be omitted and the equation was revised as follows [14].

$$
\begin{aligned}
& \int_{V^{E}}\left(\stackrel{\circ}{\sigma_{i j}}-2 \sigma_{i k} \dot{\varepsilon}_{k j}\right) \delta \dot{\varepsilon}_{i j} d V+\int_{V^{E}} \sigma_{j k} L_{i k} \delta L_{i j} d V=\int_{S_{f}} \stackrel{\bullet}{f} \delta v_{i} d S \\
& \stackrel{\circ}{\sigma_{i j}}=\dot{\sigma}_{i j}-\omega_{i k} \sigma_{k j}+\sigma_{i k} \omega_{k j} \\
& -\omega_{i k}=\frac{1}{2}\left(\frac{\partial v_{k}}{\partial x_{i}}-\frac{\partial v_{i}}{\partial x_{k}}\right),-\omega_{k j}=\frac{1}{2}\left(\frac{\partial v_{j}}{\partial x_{k}}-\frac{\partial v_{k}}{\partial x_{j}}\right)
\end{aligned}
$$

where $\stackrel{\circ}{\sigma} \underset{i j}{ }$-Jaumann differential of Cauchy stress; $\sigma$-Cauchy stress tensor; $\dot{\varepsilon}-$ Cauchy strain rate tensor; $L$-velocity gradient matrix; $v_{i}$-velocity; $d S$-differential surface area after deformation; $\dot{f}$-rate of unit surface force; $d V$ —differential volume after deformation.

The common equations in finite element were also included.

$$
\begin{aligned}
& \{v\}=[N]\{\dot{d}\} \\
& \{\dot{\varepsilon}\}=[B]\{\dot{d}\} \\
& \{L\}=[E]\{\dot{d}\}
\end{aligned}
$$

where $[N]$ is the shape function, $\{\dot{d}\}$ the nodal velocity, $[B]$ the strain rate-velocity matrix, and $[E]$ the velocity gradient-velocity matrix. With finite element discretization, the rigid governing equation for large deformation is

$$
[K]\{\Delta u\}=\{\Delta F\}
$$


where

$$
[K]=\sum_{\langle E\rangle} \int_{V^{E}}[B]^{T}\left(\left[C^{e p}\right]-[Q]\right)[B] d V+\sum_{\langle E\rangle} \int_{V^{E}}[E]^{T}[Z][E] d V
$$

$[K]$ is generally regarded as the overall elasto-plastic stiffness matrix, $\{\Delta u\}$ the nodal displacement increment, $\{\Delta F\}$ the nodal force increment, $[Q]$ and $[Z]$ the stress modified matrix, and [ $\left.{ }^{e p}\right]$ the elasto-plastic stress-strain matrix. The shear strain $\gamma_{x z}$ and $\gamma_{y z}$ of the thin plate element is set to 0 during deformation, and the selective reduced integration (SRI) could effectively deal with the forming process [15]. Selective reduced integration $K$ has been clearly described in the finite element developed by Hughes $[16,17]$.

\subsection{Scale Factor for the Sheet Metal Forming Process}

The resolution of problems in plasticity requires equations that describe the strain dependence of the flow stress. To model this dependence, several empirical formulations have been suggested. In cold working processes, in which strain hardening is prevalent, the mechanical behavior is usually described by parabolic equations, such as those suggested by Swift [18], shown in Equation (9):

$$
\bar{\sigma}=K\left(\varepsilon_{0}+\overline{\varepsilon_{p}}\right)^{n}
$$

where $\bar{\sigma}$ and $\overline{\varepsilon_{p}}$ are the equivalent stress and strain, respectively. $K, n$, and $\varepsilon_{0}$ are constants for a particular material, determined in uniaxial tension tests.

The size effect can be neglected when the thickness of the metal sheet is more than $1.0 \mathrm{~mm}$; however, with metal less than $1.0 \mathrm{~mm}$ in thickness, the size effect becomes crucial. The thickness of metal sheets used in forming processes was in the micron range, and since the traditional Swift material model was unsuitable, a new material model was needed. In this study, the applied sheet metal thickness was $50 \mu \mathrm{m}$, which was regarded as a forming process to consider the size effect. The thickness of sheet metal was considered in the traditional material model for amendment of stress-strain relations. Consequently, Equation (9) was amended as follows [19]:

$$
\bar{\sigma}(t, \bar{\varepsilon})=a K e^{b t}\left(\varepsilon_{0}+\overline{\varepsilon_{p}}\right)^{n\left(c e^{d t}-1\right)}
$$

where $a, b, c$, and $d$ are the correction values, and $t$ is the sheet thickness. Liu [20] noted that the least squares method can be used to obtain the correction values in Equation (10).

The values for $a, b, c$, and $d$, obtained from the research results of Liu [20], were substituted in Equation (10); see Equation (11) below:

$$
\bar{\sigma}(t, \bar{\varepsilon})=0.73667 K e^{0.3152 t}\left(\varepsilon_{0}+\overline{\varepsilon_{p}}\right)^{n\left(1.0106 e^{-0.01029 t}-1\right)}
$$

In this study, finite element analysis was carried out for the modified material model Equation (11), and experiments were also carried out to verify the credibility of the modified models.

\section{Numerical Analysis and Experiments}

The shell elements of the four nodes of a quadrangle were applied to deduce the stiffness matrix, which was processed using CAD. The blank shape was segmented by a mesh and transformed into data for numerical analysis by the elasto-plastic 3D finite element program. The simulated results were output to CAD for analysis. The results were displayed as deformation diagrams showing stress-strain distribution. The coefficient of friction, sheet thickness, and punch fillet radius parameters were changed to determine the relationships between punch load and punch stroke, the distribution of maximum stress and strain, and thickness distribution.

The difference between the simulation results in the modified material model and the experimental results obtained in the square hole-flange deformation process were studied and discussed. 


\subsection{Numerical Simulation Analysis Process}

Numerical simulation was carried out as follows:

1. 3D models of molds and blanks were drawn using BSE and DFE design.

2. The mesh for the 3D model was set and preprocessing was done in the file format specified by Dynaform.

3. Dynaform was used to set the process parameters of the mold and plate data files and conduct numerical analysis using the LS-DYNA program.

4. Dynaform was used to postprocess the calculations and the analytical results were then output and examined using both graphics and animation programs.

5. The data from numerical analysis was compared with the experimental results using computer integration.

6. The procedure was analyzed using the fillet and diameter of the hole of the blank and the punch fillet as parameters.

To reduce analytical and preprocessing time, only a quarter of the square holed flange was used for simulation because it was completely symmetrical. After the blank was divided, the total number of elements and nodes were 11,000 and 12,300 , respectively. The fabricated molds and the metal sheets were meshed and divided. The mold and the blank were meshed by surface division, the meshed data were converted into data files suitable for the LS-DYNA program, which was then used to carry out numerical analysis.

The friction coefficient $\mu$, set as 0.1 in simulation analysis, was close to the actual friction value obtained [21,22]. The simulation results for punch load, punch stroke, and stress and strain were output to Dynaform for postprocessing and subsequent analysis. During the postprocessing, the deformation history diagram was visualized, as were the stress and strain distribution diagrams for punch stroke in each stage. These data can serve as a reference for mold design and drawing procedures to determine the probability of cracks or wrinkles. This will reduce the time and costs that are generally associated with traditional trial-and-error methods.

\subsection{Experiment}

The test material used was SUS304 thin stainless steel sheet provided by Kita Sangyo Co Ltd., Nara, Japan and the chemical composition of the material is shown in Table 1.

Table 1. Chemical composition of SUS304 stainless steel (unit: \%).

\begin{tabular}{ccccccc}
\hline $\mathbf{C}$ & $\mathbf{S i}$ & $\mathbf{M n}$ & $\mathbf{P}$ & $\mathbf{S}$ & $\mathbf{N i}$ & $\mathbf{C r}$ \\
\hline 0.08 & 0.48 & 0.75 & 0.58 & 0.008 & 9.12 & 18.29 \\
\hline
\end{tabular}

Because the mold gap in this experiment was extremely small and processing was not easy, micro-discharge machining technology was used for fabrication, reducing die processing time and cost as well as fulfilling the accuracy requirements. Figure 1a and Table 2 show the die and the size parameters used for hole-flanging. Figure $1 \mathrm{~b}$ and Table 3 show the material flake and the size parameters used. The mechanical properties and material parameters of SUS304 stainless steel are shown in Table 4.

Table 2. Relevant parameters of the flange die. (unit: $\mathrm{mm}$ ).

\begin{tabular}{cccc}
\hline & Model 1 & Model 2 & Model 3 \\
\hline $\mathrm{P}_{\mathrm{W}}$ & 10.00 & 5.00 & 2.50 \\
$\mathrm{D}_{\mathrm{W}}$ & 10.44 & 5.22 & 2.61 \\
$\mathrm{R}_{\mathrm{p}}$ & 1.00 & 0.50 & 0.25 \\
$\mathrm{R}_{\mathrm{d}}$ & 1.20 & 0.60 & 0.30 \\
\hline
\end{tabular}




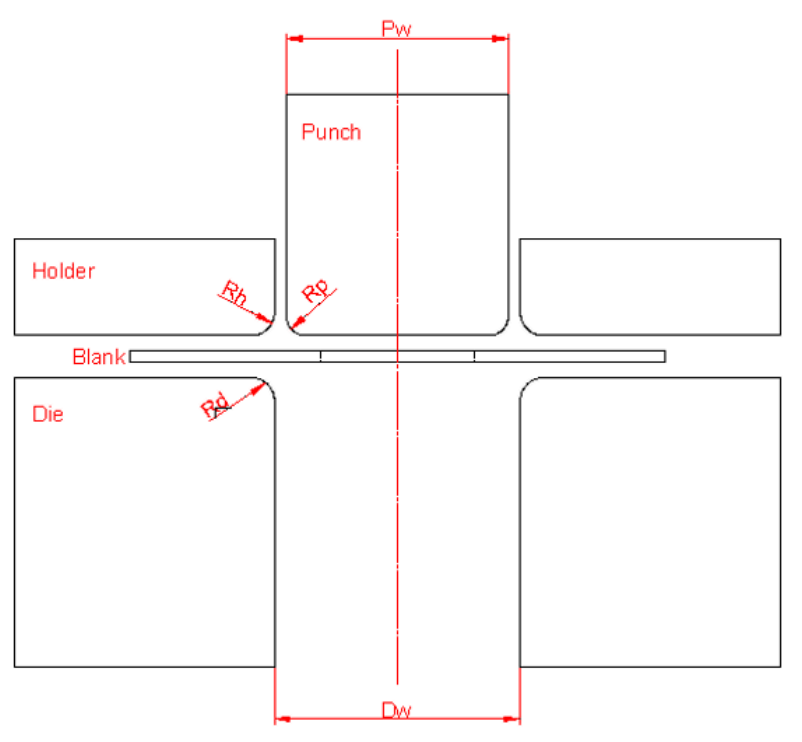

(a)

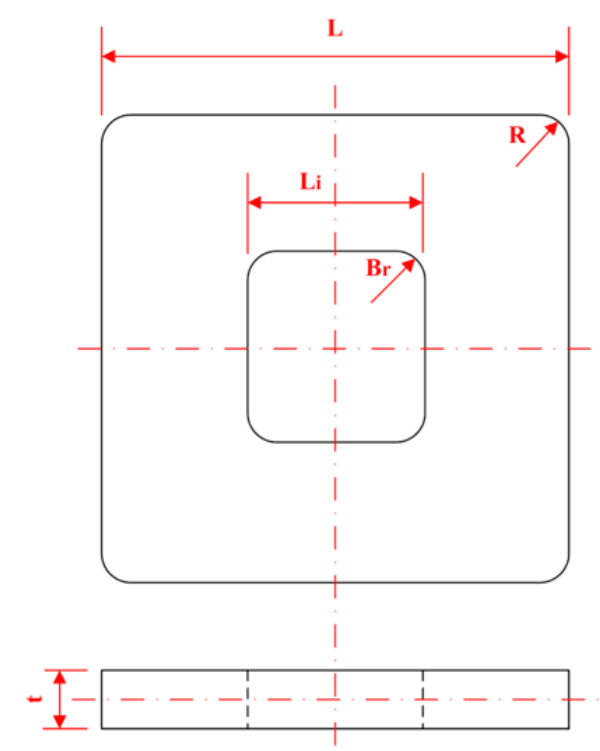

(b)

Figure 1. (a) Stretch module of the flange with a square hole; (b) stainless steel sheet with a square hole.

Table 3. Parameters and dimensions of the flange. (unit: $\mathrm{mm}$ ).

\begin{tabular}{cccc}
\hline & Model 1 & Model 2 & Model 3 \\
\hline $\mathrm{L}$ & 20 & 10 & 5 \\
$\mathrm{~L}_{\mathrm{i}}$ & 9 & 4.5 & 2.25 \\
$\mathrm{R}$ & 5 & 2.5 & 1.5 \\
$\mathrm{Br}$ & 1.6 & 0.8 & 0.4 \\
$\mathrm{t}$ & 0.2 & 0.1 & 0.05 \\
\hline
\end{tabular}

Table 4. Mechanical properties and material parameters of SUS304 stainless steel.

\begin{tabular}{ccccccc}
\hline Material & $\boldsymbol{E}(\mathrm{GPa})$ & $\boldsymbol{v}$ & $\sigma_{\boldsymbol{y}} \mathbf{( M P a )}$ & $\boldsymbol{K} \mathbf{( M P a )}$ & $\boldsymbol{n}$ & $\varepsilon_{\mathbf{0}}$ \\
\hline Model 1 & 207 & 0.3 & 362 & 1427.2 & 0.5809 & 0.077 \\
\hline Model 2 & 207 & 0.3 & 341 & 1382.9 & 0.5815 & 0.077 \\
\hline Model 3 & 198 & 0.3 & 306 & 1361 & 0.582 & 0.077 \\
\hline
\end{tabular}

Where E-Young's modulus; $v$-Poisson's ratio; $\sigma_{y}$-Yield stress.

\subsubsection{Forming Process of a Flange with a Square Hole for Stainless Steel Sheets}

Figure $1 \mathrm{~b}$ and Table 5 display the geometric deformation and the stroke at five stages of hole-flanging. In the drawing process, the major deformation of the sheet metal is divided into the contact area along the punch corner and the one along the horizontal arc angle of the die, which are the drawing deformation areas. As shown in Figure 2, the die is in contact with the sheet metal while the punch moves down from S1 to S3, and the metal is gradually deformed by the punch and moves across the die as the punch corner moves down until deformation is complete. When the stroke reaches S3, the sheet metal has been completely penetrated as the punch continues moving in the $-\mathrm{Z}$ direction. The area of the sheet metal contacting the punch corner undergoes the largest deformation and bears the maximum amount of circular drawing stress, which is gradually released as the stroke moves to S4. 
Table 5. Relevant stroke parameters of the flange (unit: $\mathrm{mm}$ ).

\begin{tabular}{cccc}
\hline Step & Model 1 & Model 2 & Model 3 \\
\hline $\mathrm{S}_{1}$ & 0.00 & 0.00 & 0.000 \\
$\mathrm{~S}_{2}$ & 1.75 & 0.75 & 0.375 \\
$\mathrm{~S}_{3}$ & 3.00 & 1.50 & 0.750 \\
$\mathrm{~S}_{4}$ & 5.25 & 2.25 & 1.125 \\
$\mathrm{~S}_{5}$ & 7.00 & 3.00 & 1.500 \\
\hline
\end{tabular}
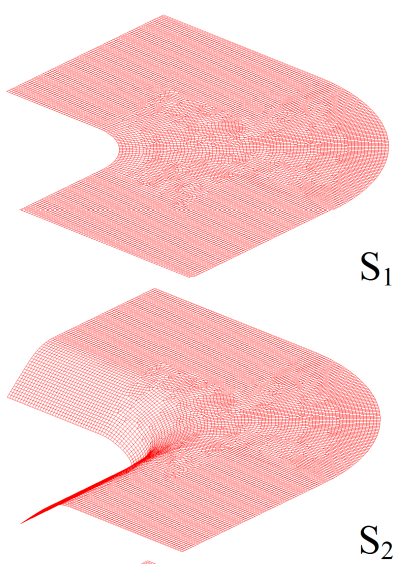

$\mathrm{S}_{2}$

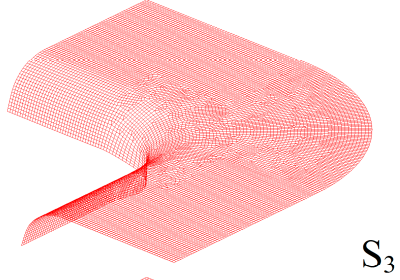

$\mathrm{S}_{3}$

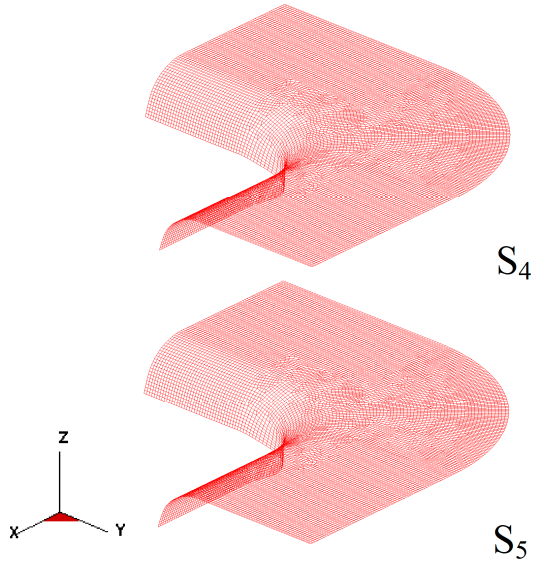

Figure 2. Tensile deformation history of the flange.

\subsubsection{Experimental Setup}

Figure 3 shows the electronic press used in the experiments in which sets of three different scaled-down hole-flanged samples were processed. The stress-displacement data acquired in the experiments was used to prepare diagrams, which were compared with those from simulation data. Figure 4 a shows the die components. The punch design is hierarchical and aimed to enhance rigidity. SDK11 tool steel, which has excellent properties for die-making, was used for the punch and die to ensure the highest mechanical properties and wear-resistance. Figure $4 \mathrm{~b}$ shows the three different sized samples used in the experiments. 


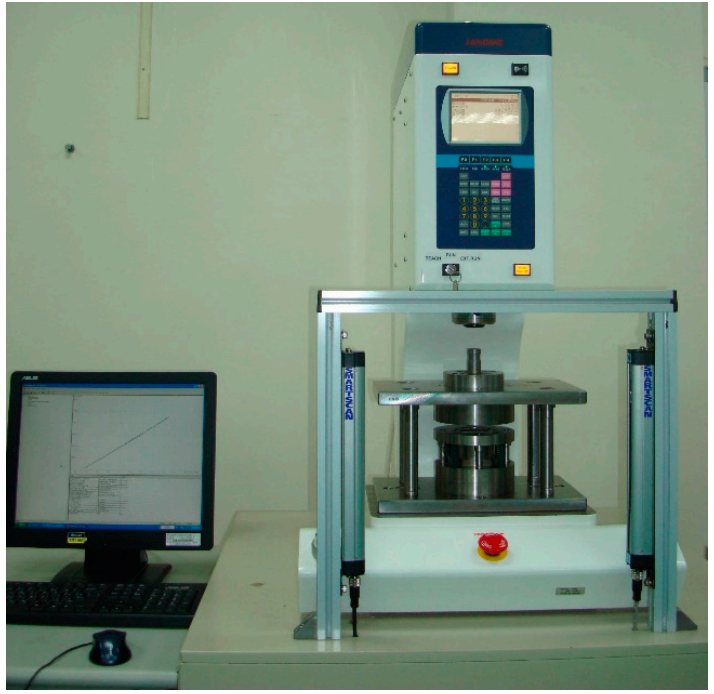

Figure 3. The micro-electronic press.

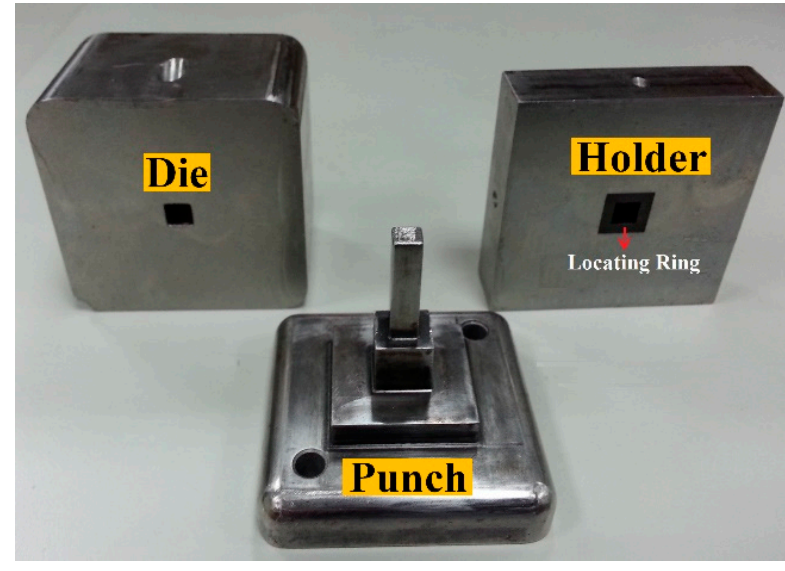

(a)

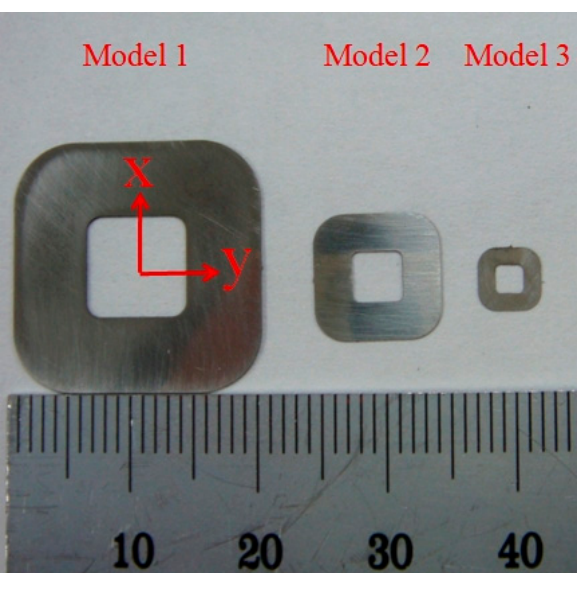

(b)

Figure 4. (a) Key components of the mold; (b) SUS304 stainless steel workpiece specimens used in the experiments.

\section{Results and Discussion}

The final specimens, stainless steel sheets with square flanged holes after punching and rebound, are shown in Figure 5.

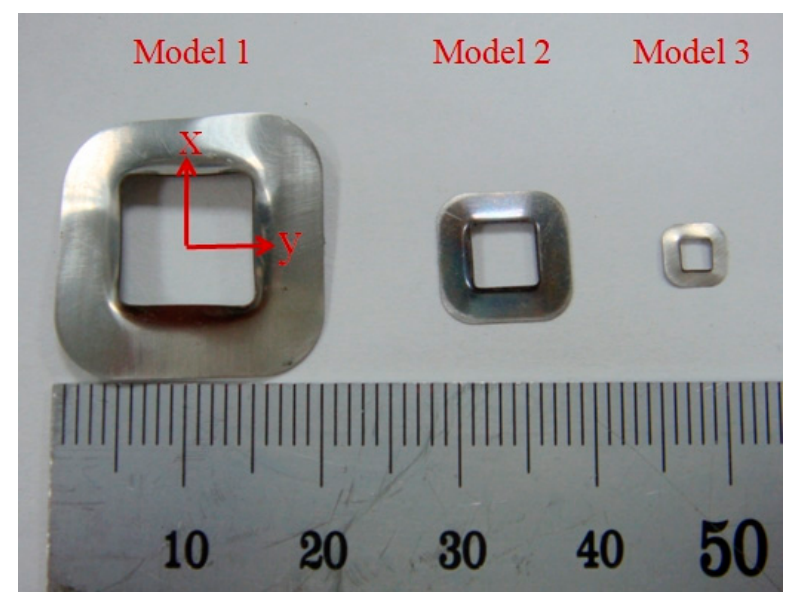

Figure 5. Three stainless steel specimens after punching and rebound. 


\subsection{Influence of the Fillet Radius of the Hole on the Drawing Process}

Process analysis was carried out for changes in fillet radius of the hole in the sample sheets. The radius of the fillet of the hole $(\mathrm{Br})$ in the different model blanks is shown in Table 6 . The material parameter values were corrected by a scale factor and the material was regarded as being isotropic.

Table 6. The fillet radius and related parameters of the hole in the stainless steel sheet (unit: $\mathrm{mm}$ ).

\begin{tabular}{cccccccc}
\hline Model No. & & Br & & $t$ & Final Stroke \\
\hline Model 1 & 1.2 & 1.4 & 1.6 & 1.8 & 2 & 0.2 & 7 \\
Model 2 & 0.4 & 0.6 & 0.8 & 1.0 & 1.2 & 0.1 & 3 \\
Model 3 & 0.2 & 0.3 & 0.4 & 0.5 & 0.6 & 0.05 & 1.5 \\
\hline
\end{tabular}

\subsubsection{Relationship between the Load and Stroke of the Punch with Different $\mathrm{Br}$}

As shown in Figure 6, the load on the punch increases rapidly as the punch touches the sheet. During the drawing process, the load dropped off rapidly after the square punch had penetrated the blank. The results show that the load remained small after penetration until the punching had been completed. However, the load fluctuates after penetration, mainly due to the extension of the sheet material into the lower mold. Elastic recovery and a spring forward phenomenon caused by repeated contact and separation of the punch and sheet also occurred. So, the oscillations present in the force evolutions are not resulting from sharp variations of the internal strain energy. The figures show that the load on the punch increased with an increase in $\mathrm{Br}$, which was mainly caused by an increase in the area of contact between the punch and the sheet.

The three models (see Figure 6) were analyzed with the related parameters shown in Table 6. The stroke parameters used for model 1 are shown in Table 5, and the high peak for a displacement of $2 \mathrm{~mm}$ occurs between the S2 and S3 strokes. As the area of contact between the punch and the material increases, so does the load on the punch as it penetrates the blank during the S1 stroke, and at this time, the load reaches its maximum (see Figure 6a); the forces at the four corners of the square hole make a large contribution to this. From stroke position S2, the flange is being drawn and the punch is in continuous contact with the material. When it reaches $\mathrm{S} 3$, at a displacement of $2 \mathrm{~mm}$, the load on the punch rises again to a peak (see Figure 6a), after which the load drops to almost zero after the punch has fully penetrated the material.

\subsubsection{The Relationship between the Fillet Radius of the Hole and Maximum Principal Stress/Strain}

The maximum stress and strain occur in the contact area between the sheet and the corner of the punch as shown in Figures 7a and 8a. The maximum principal stress increases as the value of $\mathrm{Br}$ increases, as shown in the figures. This is because the larger value of $\mathrm{Br}$ induces higher internal force in the material during forming, which causes the stress to rise. As can be seen in Figure 7c, when the thin material of Model $3(t=0.05 \mathrm{~mm})$ is formed, the flange rebounds after the punch retracts, stress is released, and strain is reduced.

A comparison of the three models shows that miniaturization of the scale allows a greater strain to be induced (see Figure 8). This is mainly because the number of crystal grains in the thinner sheets is smaller, and better plastic deformation induces more strain. The maximum principal strain increases slightly with an increase in the hole fillet radius, simply because the larger $\mathrm{Br}$ allows more extensive deformation. The average values obtained for the maximum principal strain for three models were $0.552,0.583$, and 0.611 . 


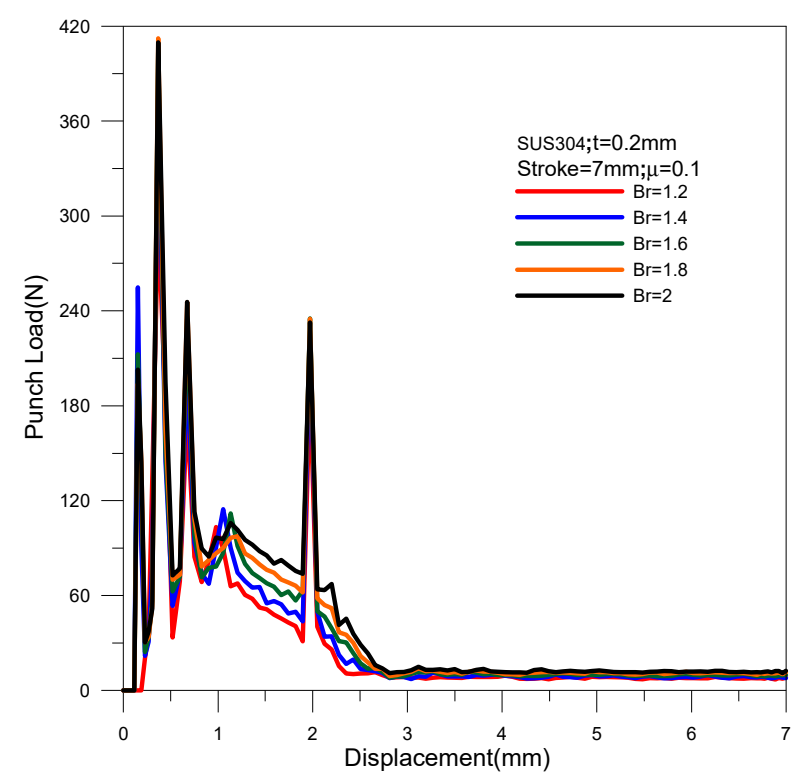

(a)

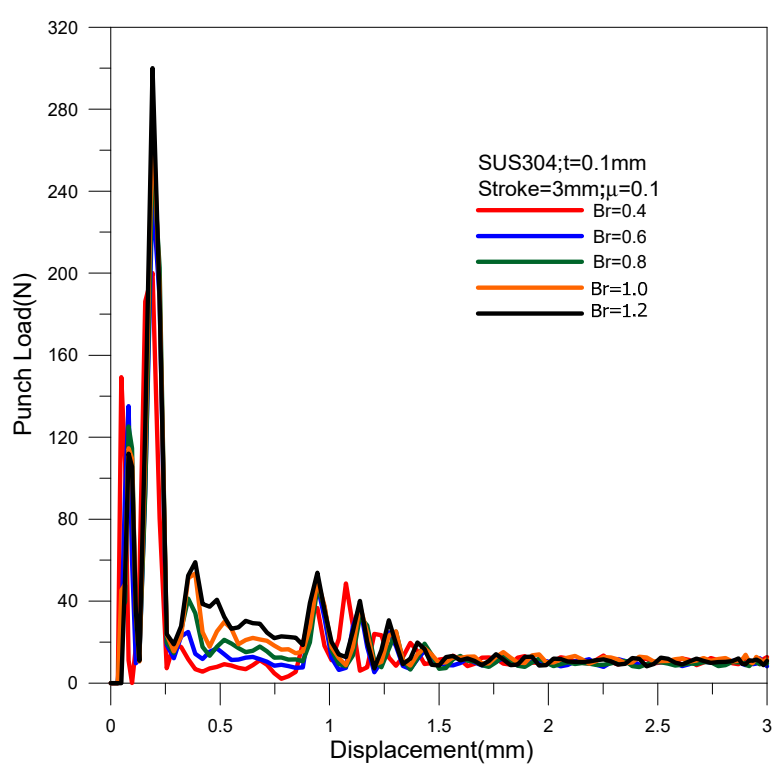

(b)

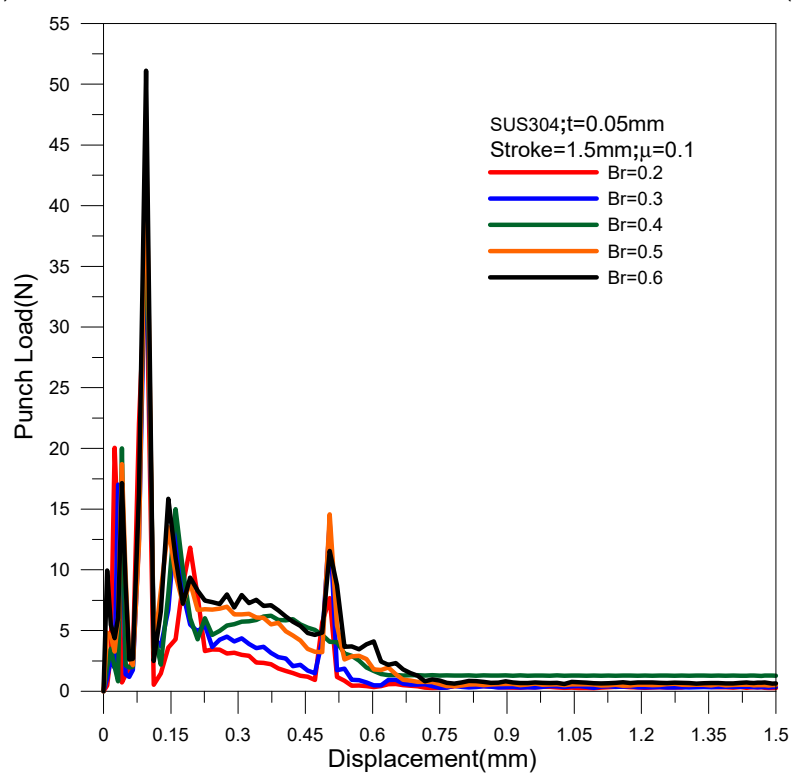

(c)

Figure 6. The relationship between the load and stroke of the punch with different values of Br: (a) Model 1; (b) Model 2; (c) Model 3.

\subsubsection{The Relationship between the Fillet Radius and the Height of the Flange}

The side view of a flange with a square hole in Figure 9a shows the location of the maximum height of the flange. Results show the height of the flange increases with an increase in the fillet radius of the hole. This is because a better forming shape allows the production of a higher flange, as shown in Figure 9. After unloading, the flange rebounds to make the height of the flange slightly less.

\subsection{The Impact of the Punch Fillet Radius on the Process}

In this section, the results of changes to the fillet radius $\left(R_{p}\right)$ of the punch are investigated and analyzed to determine their effect after the final stroke and spring-back. The radius of the punch fillet and relative parameters are shown in Table 7 . The material parameters have been corrected by a scale factor and the material has been regarded as isotropic. 
Table 7. Punch fillet radius and related parameters (unit: $\mathrm{mm}$ ).

\begin{tabular}{cccccccc}
\hline Model No. & & & $\mathbf{R}_{\mathbf{p}}$ & & & $\boldsymbol{t}$ & Final Stroke \\
\hline Model 1 & 0.6 & 0.8 & 1 & 1.2 & 1.4 & 0.2 & 7 \\
Model 2 & 0.3 & 0.4 & 0.5 & 0.6 & 0.7 & 0.1 & 3 \\
Model 3 & 0.15 & 0.2 & 0.25 & 0.3 & 0.35 & 0.05 & 1.5 \\
\hline
\end{tabular}

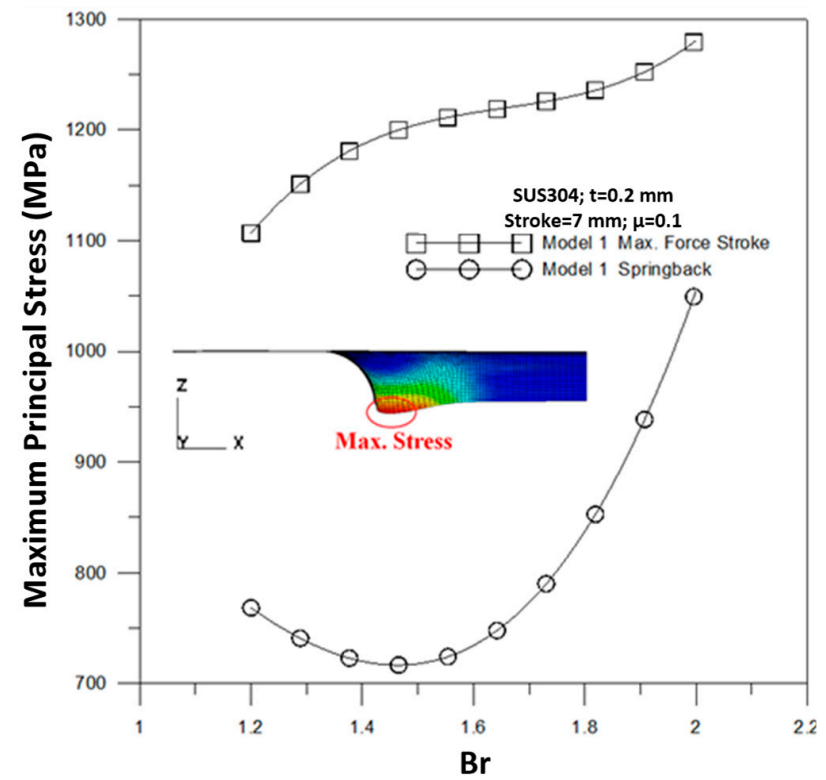

(a)

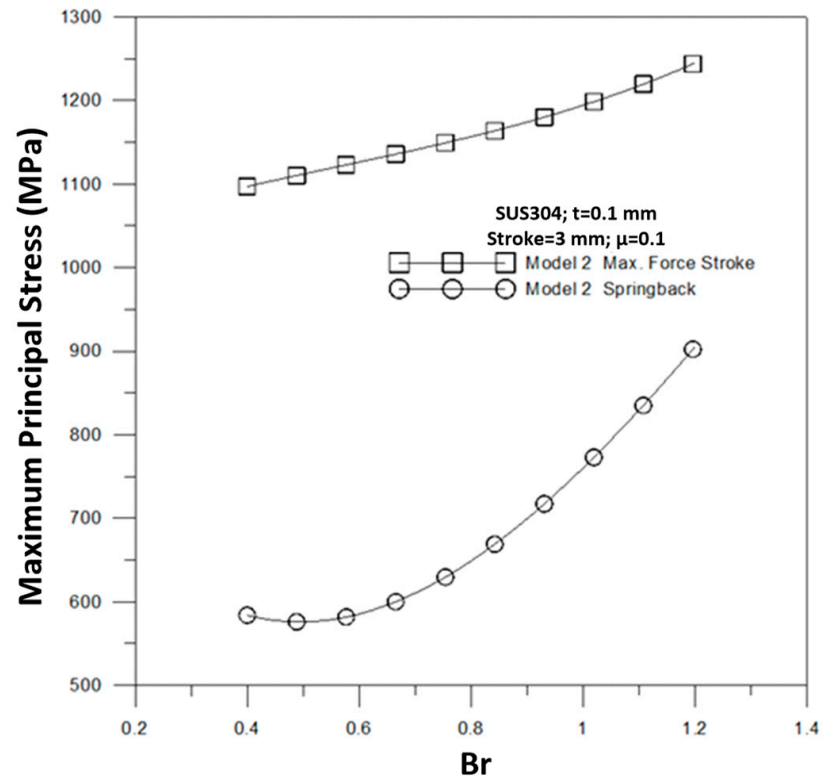

(b)

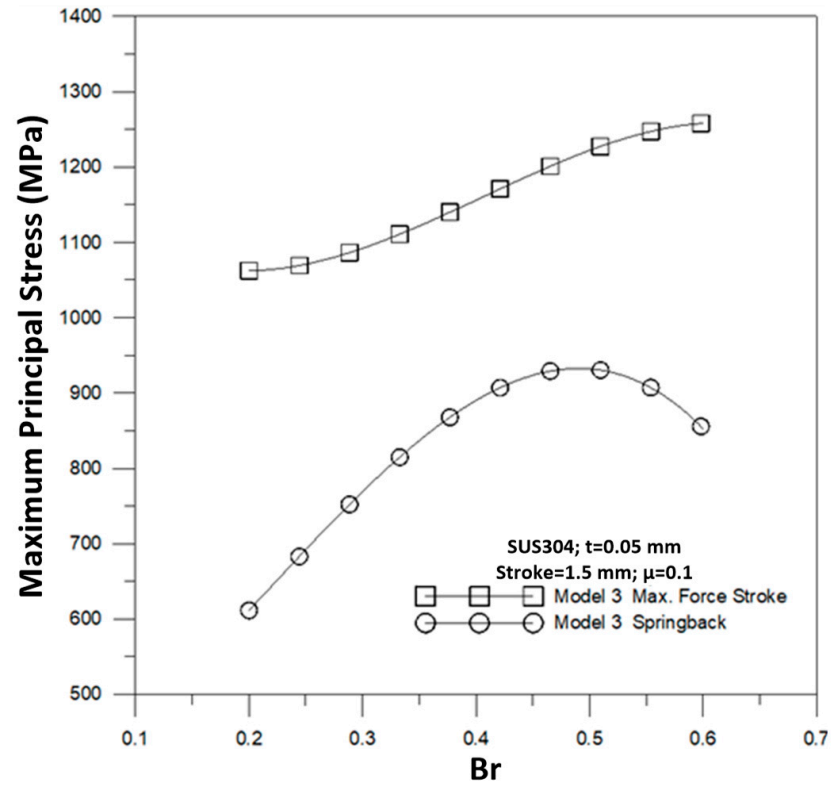

(c)

Figure 7. The relationship between the fillet radius of the hole and maximum principal stress in the material of the sheet: (a) Model 1; (b) Model 2; (c) Model 3. 


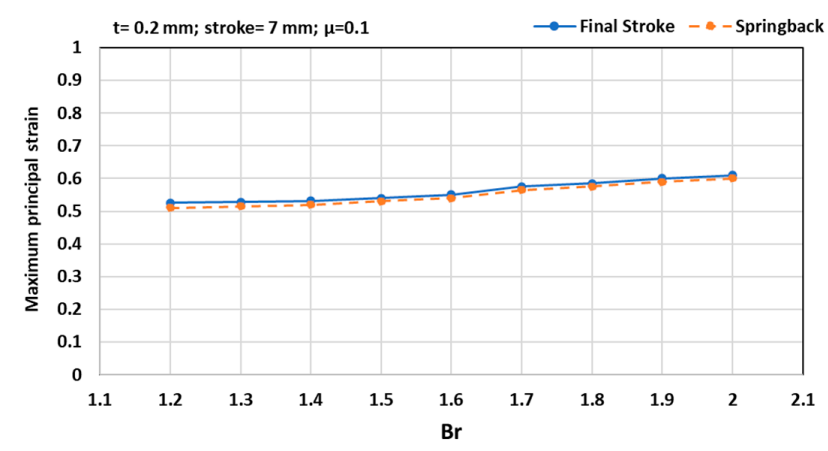

(a)

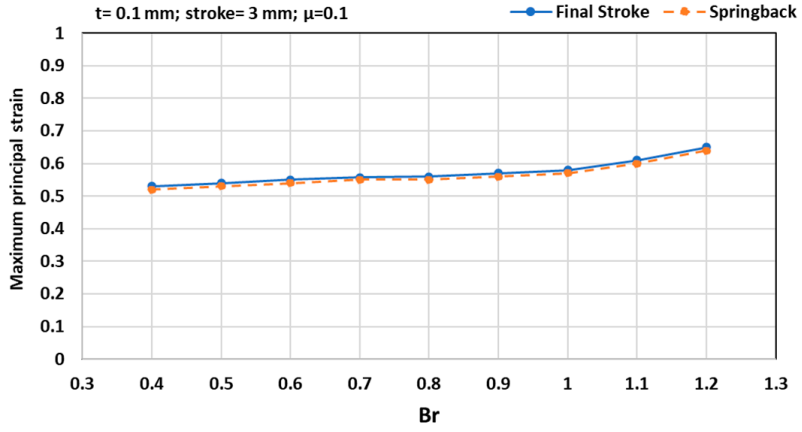

(b)

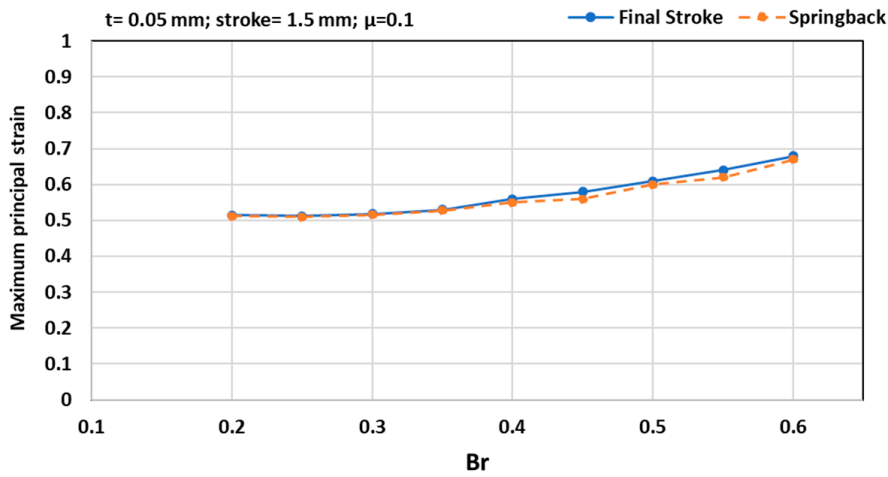

(c)

Figure 8. The relationship between the fillet radius of the hole and maximum principal strain of the flange: (a) Model 1; (b) Model 2; (c) Model 3.

4.2.1. The Relationship between the Load and Stroke of the Punch with Different $R_{p}$

In Figure 10, it can be seen that the punch load decreases with an increase in $R_{p}$, mainly because the sliding between the punch and the material that occurs during the forming stroke takes place over a greater distance. This reduces the speed of hole forming, and it is clear that a larger value of $R_{p}$ will reduce the load on the punch.

4.2.2. The Relationship between the Punch Fillet Radius and Maximum Principal Stress/Strain

Figure 11 shows the relationship between the punch fillet radius and the maximum principal stress. For Model 1, the maximum principal stress did not change very much with changes in punch fillet radius. However, in the other two models, the maximum principal stress decreased with an increase in the punch fillet radius, mainly because the larger $R_{p}$ value reduced the load and the stress during forming. This stress is relieved completely after the punch has retracted and the flanged sample has rebounded.

From Figure 12, it can be seen that the maximum principal strain decreases very slightly with an increase in punch fillet radius. The change in strain in Model 1 is 0.07 , and the average maximum principal strain approaches 0.575 . The maximum principal strain in the finished product after drawing will be concentrated in the area where the sheet is in contact with the corner of the punch, but an increase in $R_{p}$ reduces the duration of contact between the material and the rounded corners of the four sides of the square punch in this area, and so the amount of deformation is reduced.

\subsection{Influence of the Forming Ratio on the Process}

The forming ratio, $F R$, was changed to simulate some external influence on the forming process. FR and the forming limit ratio, FLR, are defined by Equations (12) and (13).

$$
F R=A_{h} / A_{p}
$$




$$
F L R=A_{h, \min } / A_{p}
$$

where $A_{p}$ and $A_{h}$ are the sectional area of the square punch and square hole before processing. $A_{h, \min }$ is the hole area without the occurrence of any cracking during the drawing process.

The value of $F R$ was determined by analysis using Dynaform to be $0.84,0.86,0.88$, and 0.9 , and the forming limit of the square hole flange was $F L R=0.84$. The forming limit diagrams are shown in Figure 13. It was found that cracks appeared in the corners of the flange, and that wrinkling occurred in the undrawn area of the sheet. The flange in Model 2 had a larger safe area than that in the other two models (see Figure 13b).

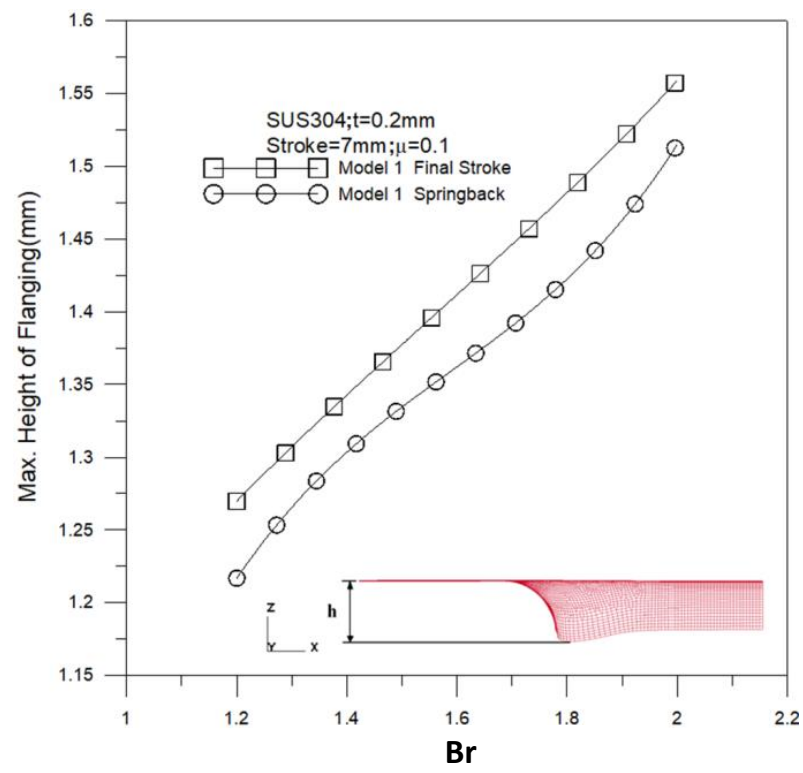

(a)

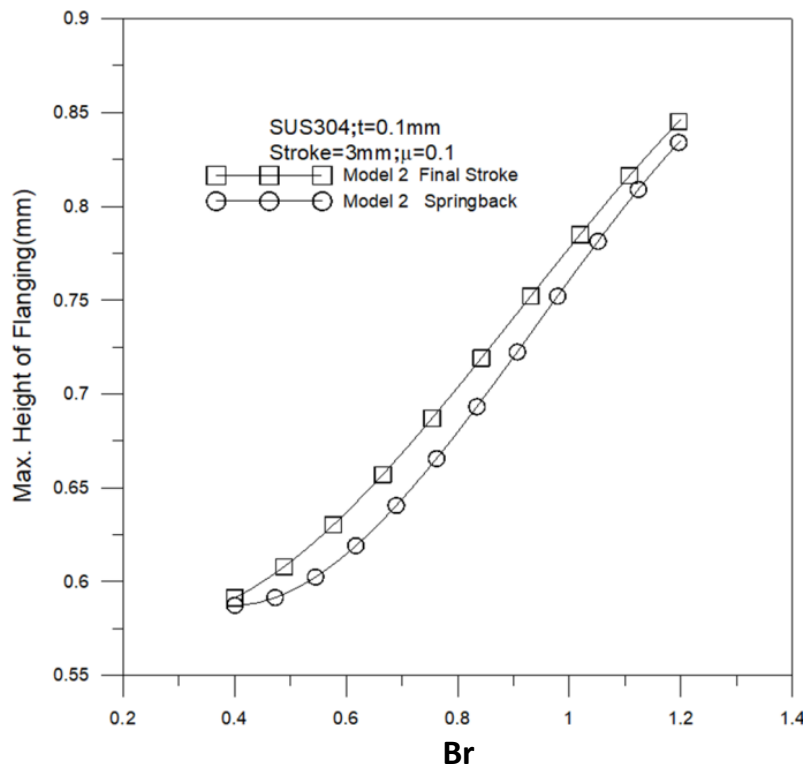

(b)

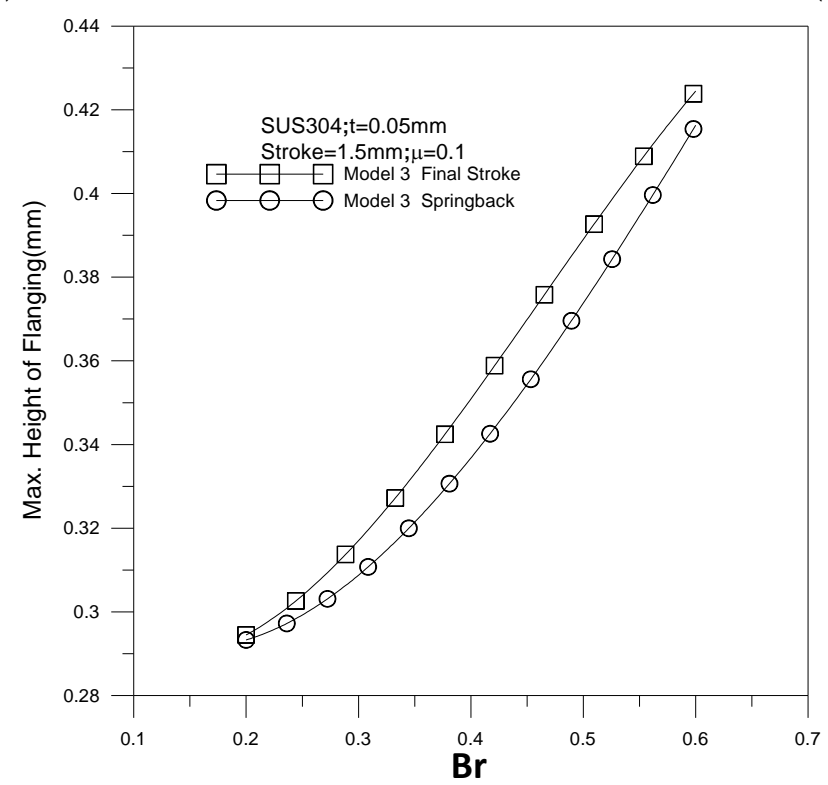

(c)

Figure 9. The relationship between the fillet radius and the height of flange: (a) Model 1; (b) Model 2; (c) Model 3. 


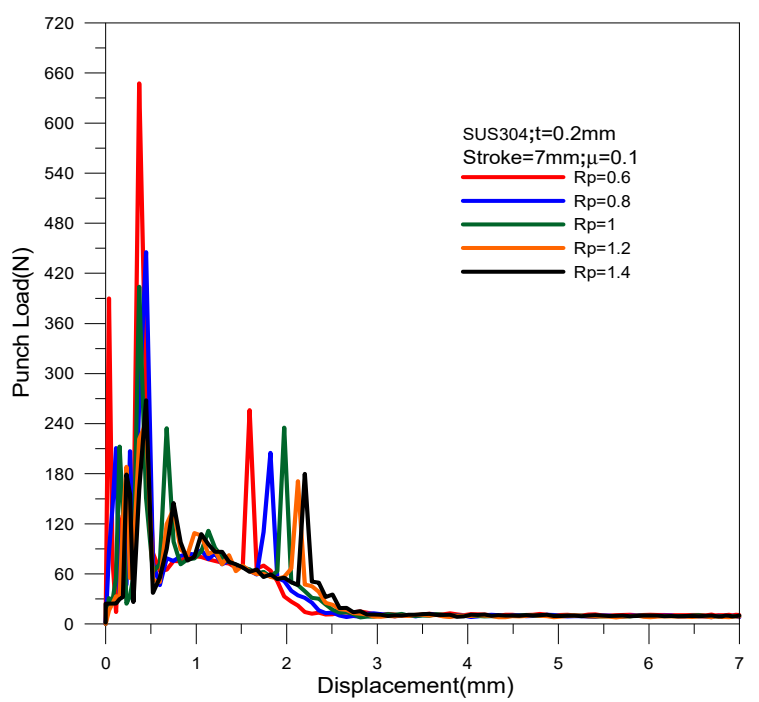

(a)

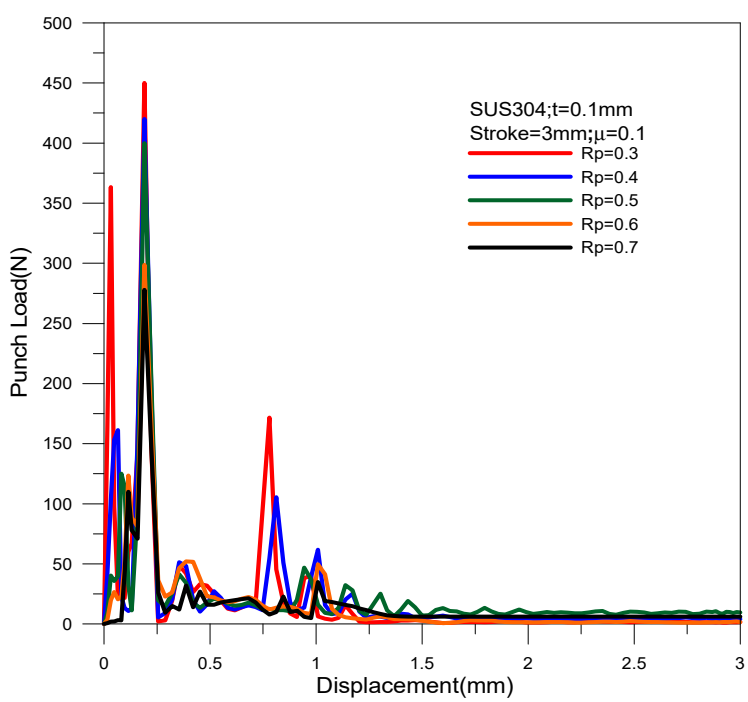

(b)

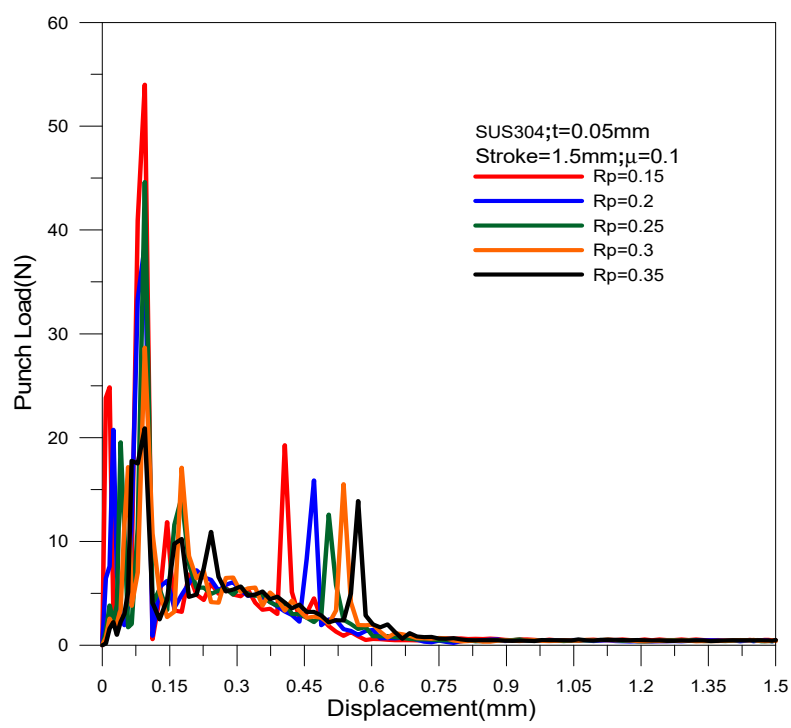

(c)

Figure 10. The relationship between the load and stroke of the punch with different $R_{\mathrm{p}}$ : (a) Model 1; (b) Model 2; (c) Model 3.

\subsubsection{The Relationship between the Load and Stroke of the Punch with Different FR}

Figure 14 is a graph of the relationship between the punch load and the stroke for different forming ratios. As shown in the figure, the punch load decreases as the value of $F R$ increases. The reason is that the larger forming ratio results in a larger hole. The contact area between the punch and the sheet is smaller, and so the load of the punch is smaller. A longer stroke must be taken with smaller values of $F R$.

4.3.2. The Relationship between the Forming Ratio and Maximum Principal Stress/Strain

Figure 15 shows the relationship between the forming ratio and the maximum principal stress in the flange. The maximum principal stress decreases with an increase in the forming ratio, and because the larger value of $F R$ draws less material, the corresponding punch load is smaller, as is the induced stress. After the punch retracts and the flange rebounds, the stress is released and reduced. 


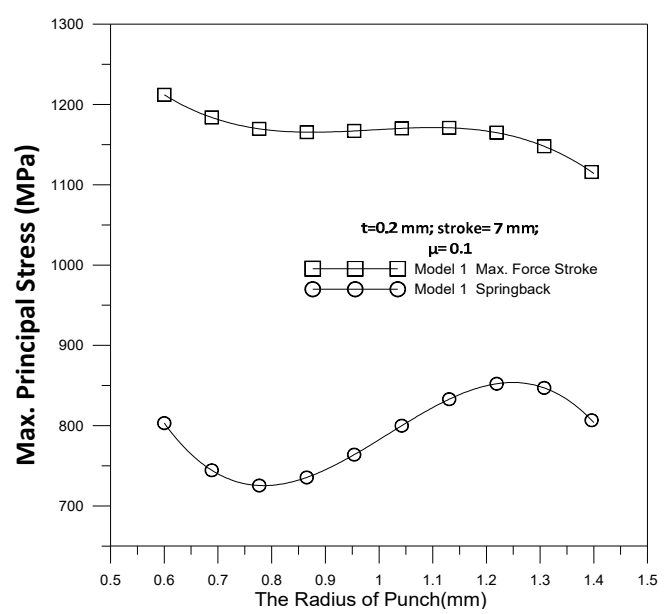

(a)

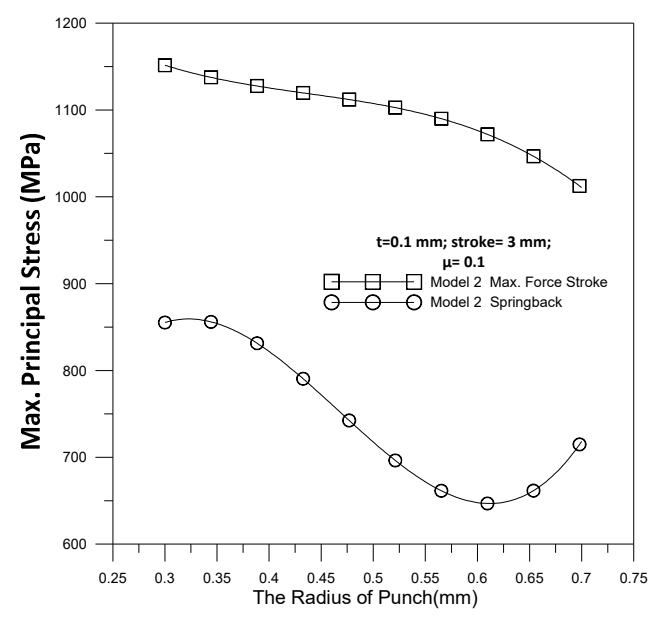

(b)

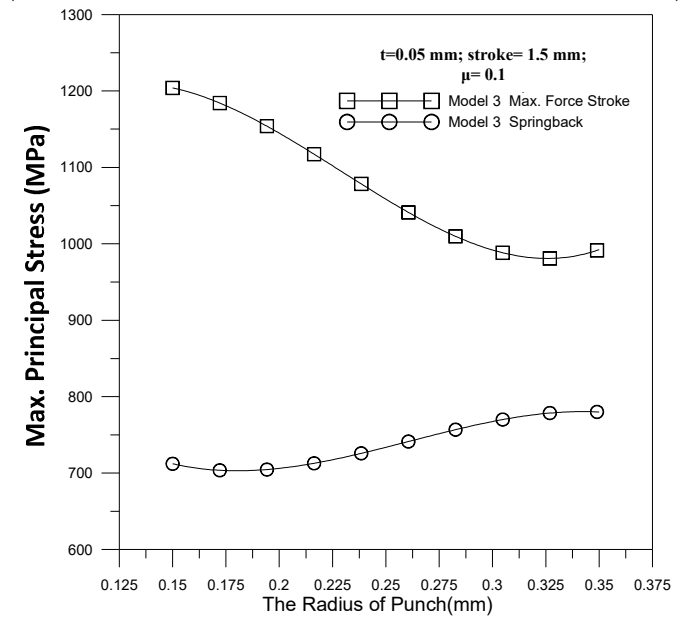

(c)

Figure 11. The relationship between the punch fillet radius and maximum principal stress: (a) Model 1; (b) Model 2; (c) Model 3 .

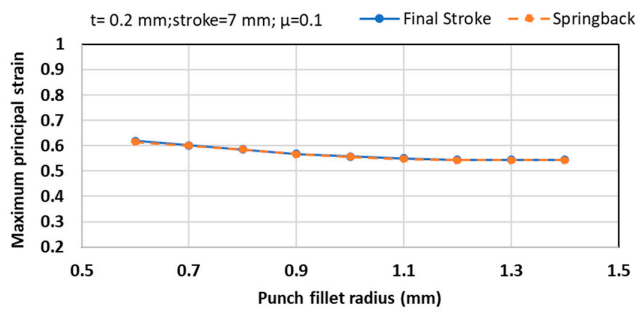

(a)

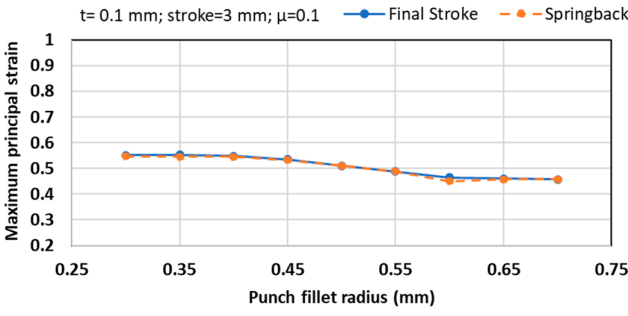

(b)

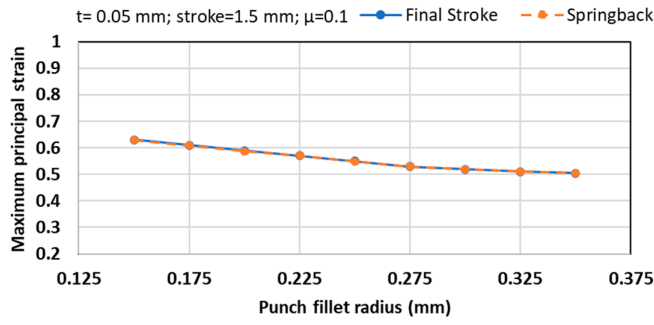

(c)

Figure 12. The relationship between the punch fillet radius and the maximum principal strain: (a) Model 1; (b) Model 2; (c) Model 3. 


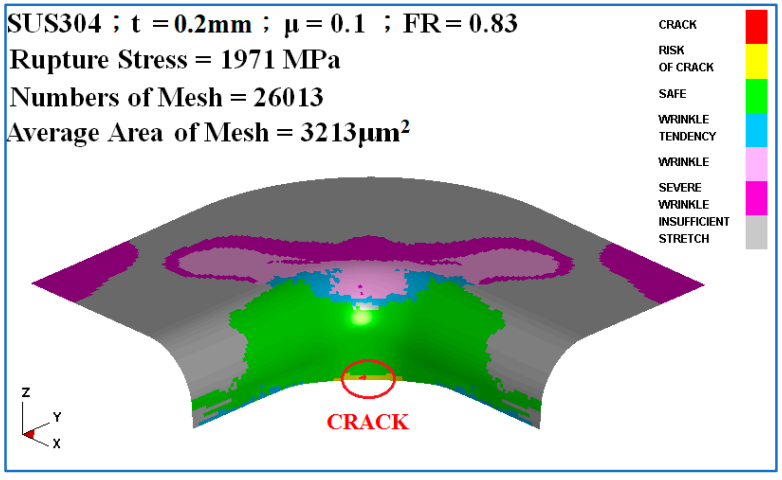

(a)

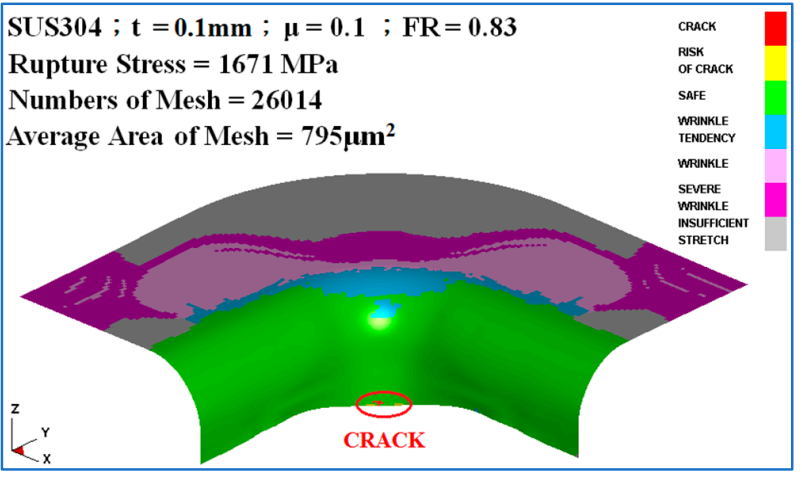

(b)

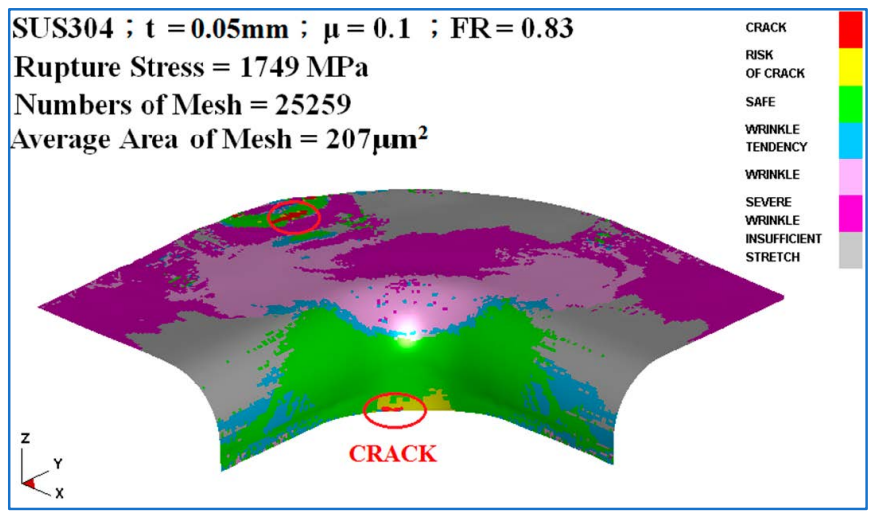

(c)

Figure 13. Sheet material forming limit diagram: (a) Model 1; (b) Model 2; (c) Model 3.

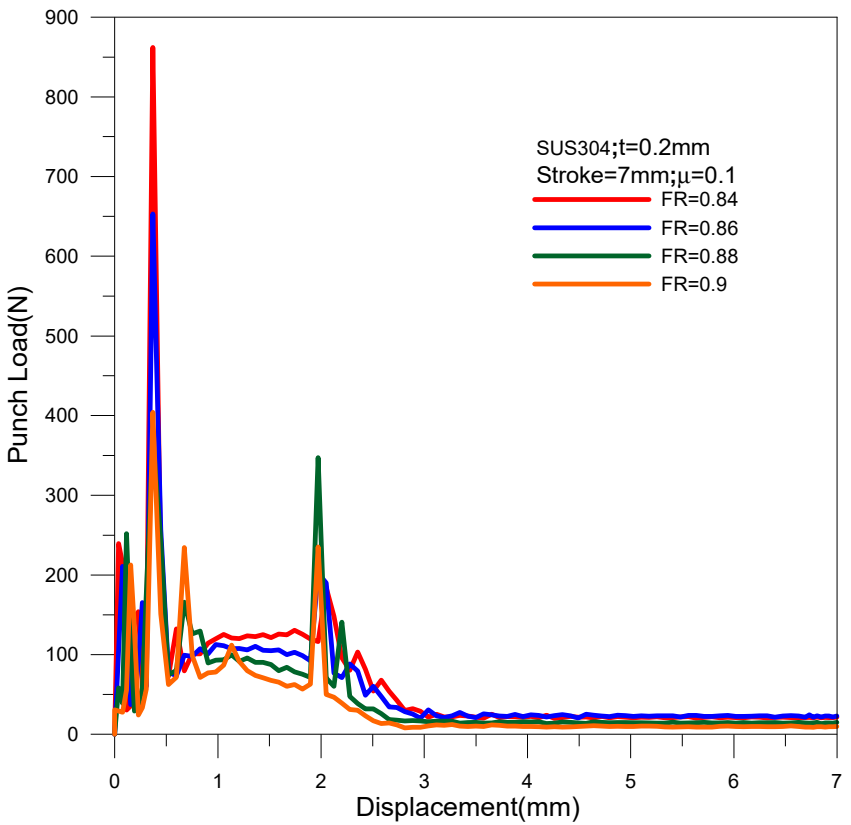

(a)

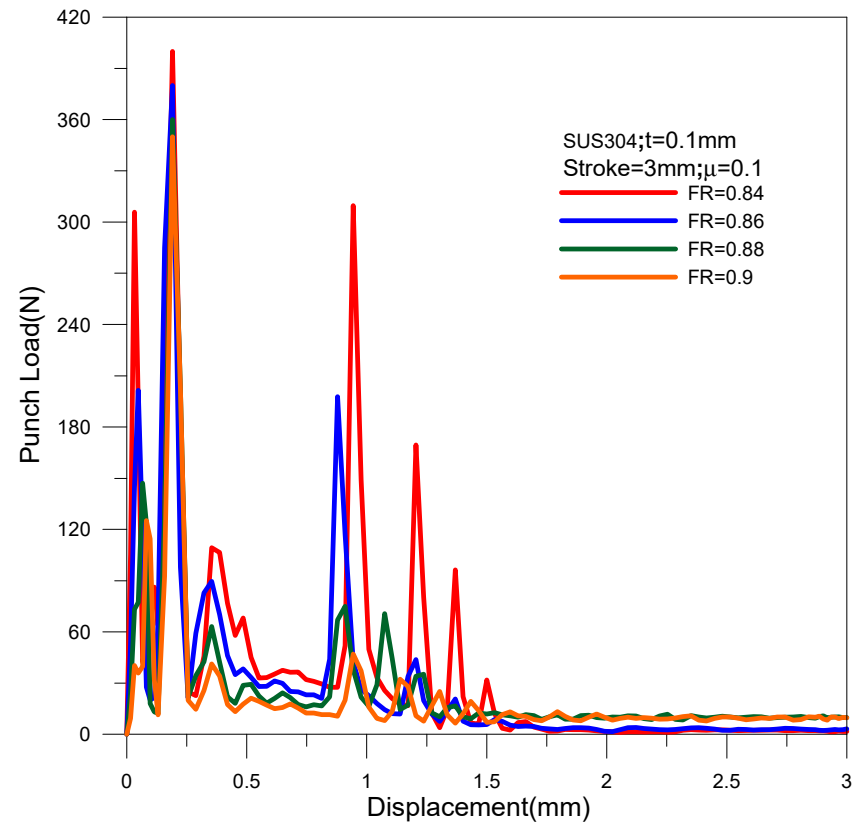

(b)

Figure 14. Cont. 


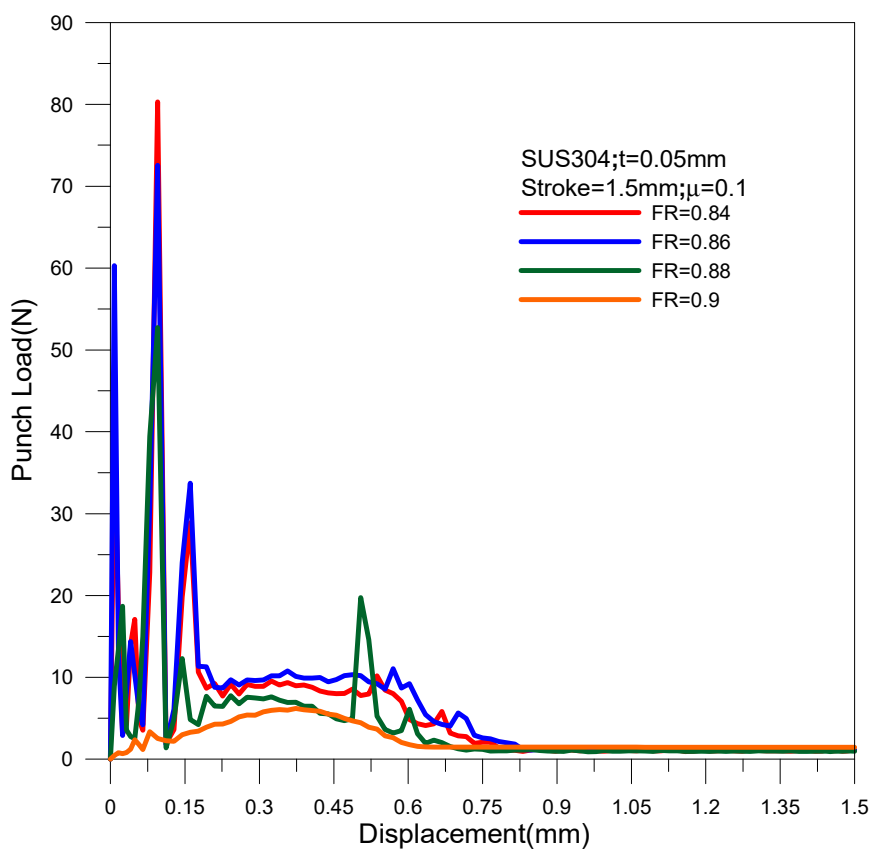

(c)

Figure 14. The relationship between the load and stroke of the punch with different FR: (a) Model 1; (b) Model 2; (c) Model 3.

Figure 16 shows the relationship between the forming ratio and the maximum principal strain in the sheet. This strain decreases as the forming ratio increases. The main reason is that the larger the $F R$, the larger the hole dimension, and the smaller the deformation of the flange, again making the strain relatively small. The strain also tends to decrease slightly after rebound.

4.3.3. The Relationship between the Forming Ratio and the Maximum Height of the Flange

Figure 17 shows the relationship between the forming ratio and the maximum height of the flange. As the forming ratio increases, the maximum flange height decreases by approximately $27.8,30$, and $35.2 \%$ for models 1,2 , and 3 , respectively. The reason for this is that the larger the $F R$, the larger the hole dimension, and the smaller the amount of stretch-deformed sheet, because less of it is drawn into the lower die.

From the results above in Sections 4.1-4.3 regarding Model 1, it is found that the average values of minimum flange thickness for variations of $\mathrm{Br}, \mathrm{R}_{\mathrm{p}}$, and $F R$ are $0.151,0.148$, and $0.143 \mathrm{~mm}$, respectively, as shown in Table 8 , and the maximum deviation approaches $5.3 \%$. For Models 2 and 3, the maximum deviations are close to 6.5 and $8.7 \%$, respectively.

Table 8. Comparisons of minimum flange thickness and maximum dimension of the hole for three models.

\begin{tabular}{|c|c|c|c|c|}
\hline Model No. & & 1 & 2 & 3 \\
\hline \multirow{4}{*}{ Minimum flange thickness (mm) } & Variations of $\mathrm{Br}$ & 0.151 & 0.0776 & 0.0378 \\
\hline & Variations of $R_{p}$ & 0.148 & 0.0775 & 0.0374 \\
\hline & Variations of $F R$ & 0.143 & 0.0725 & 0.0345 \\
\hline & average & 0.146 & 0.0758 & 0.0365 \\
\hline \multirow{4}{*}{ Maximum dimension of the hole (mm) } & Variations of $\mathrm{Br}$ & 5.09 & 2.547 & 1.274 \\
\hline & Variations of $R_{p}$ & 5.095 & 2.547 & 1.273 \\
\hline & Variations of $F R$ & 5.08 & 2.546 & 1.274 \\
\hline & average & 5.088 & 2.547 & 1.274 \\
\hline
\end{tabular}




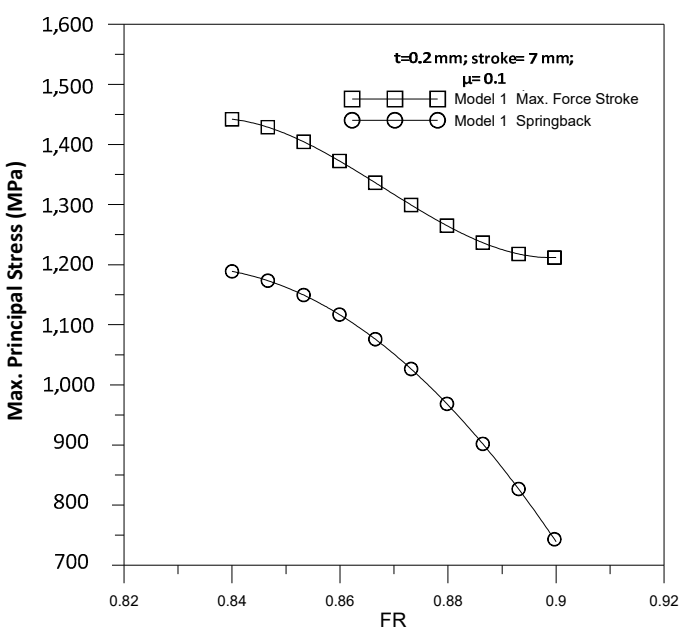

(a)

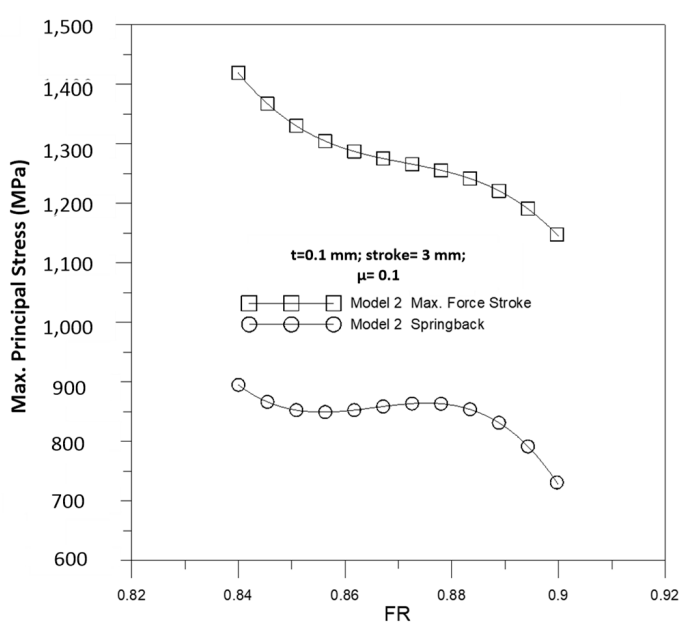

(b)

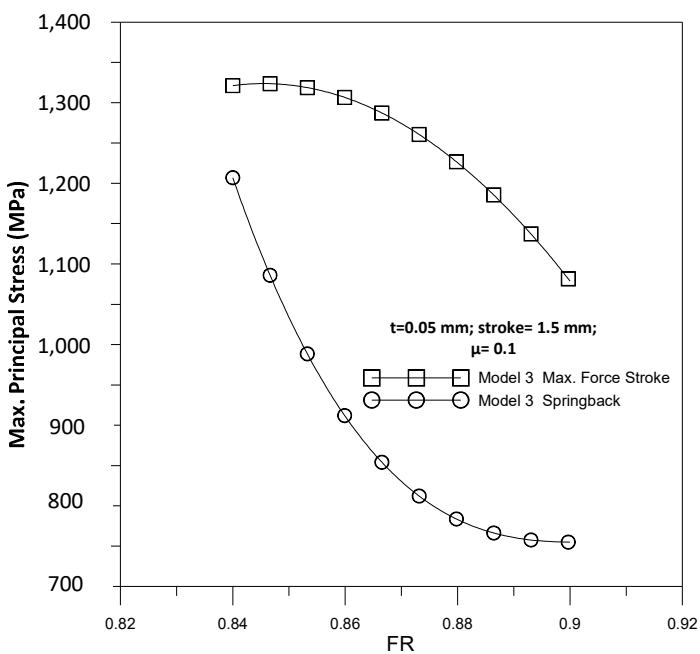

(c)

Figure 15. The relationship between the forming ratio and maximum principal stress in the flange: (a) Model 1; (b) Model 2; (c) Model 3.

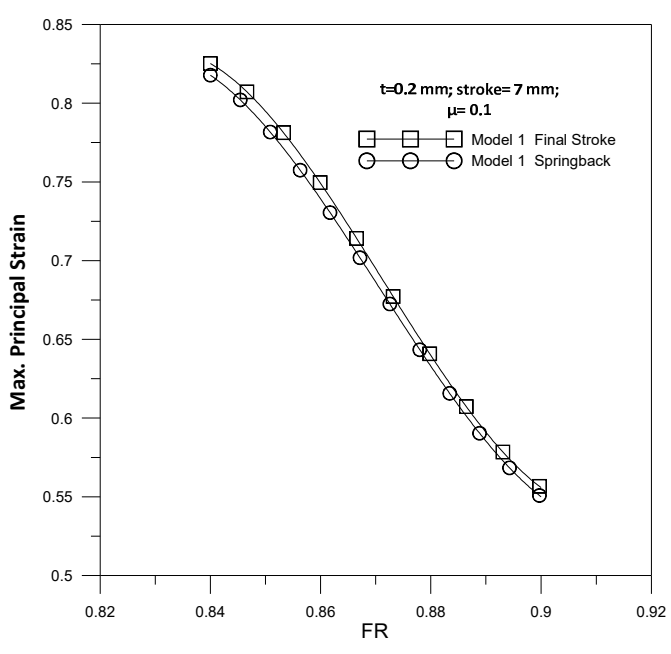

(a)

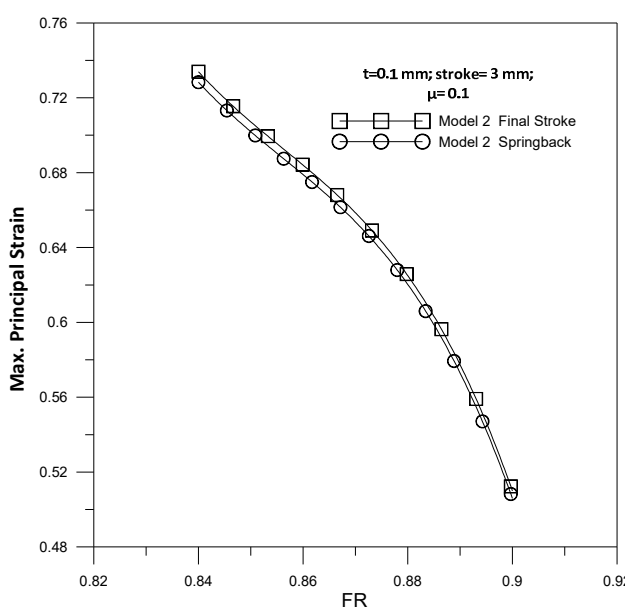

(b)

Figure 16. Cont. 


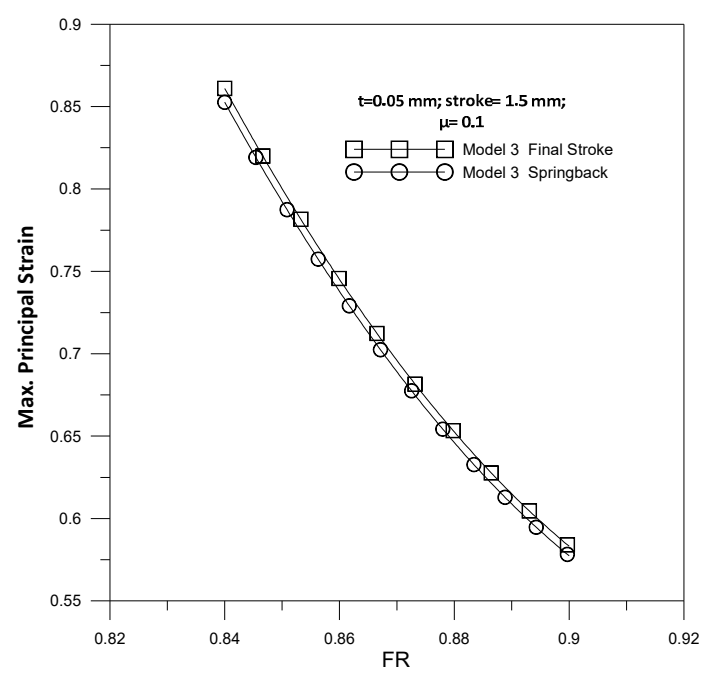

(c)

Figure 16. The relationship between the hole radius and maximum principal strain in the flange: (a) Model 1; (b) Model 2; (c) Model 3.

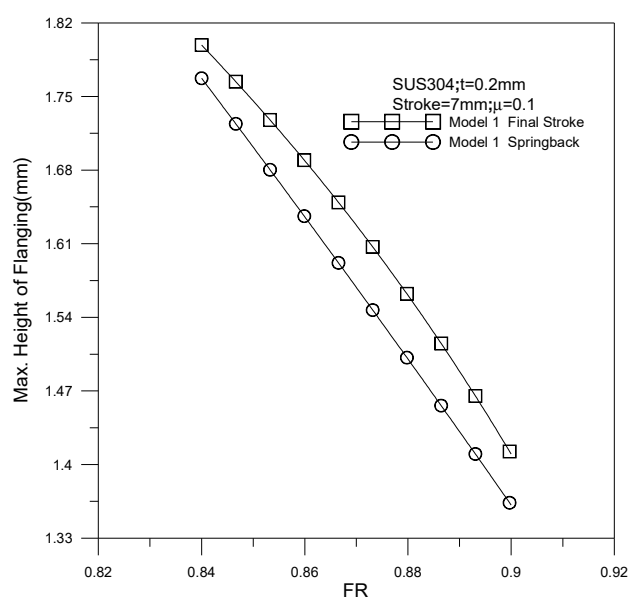

(a)

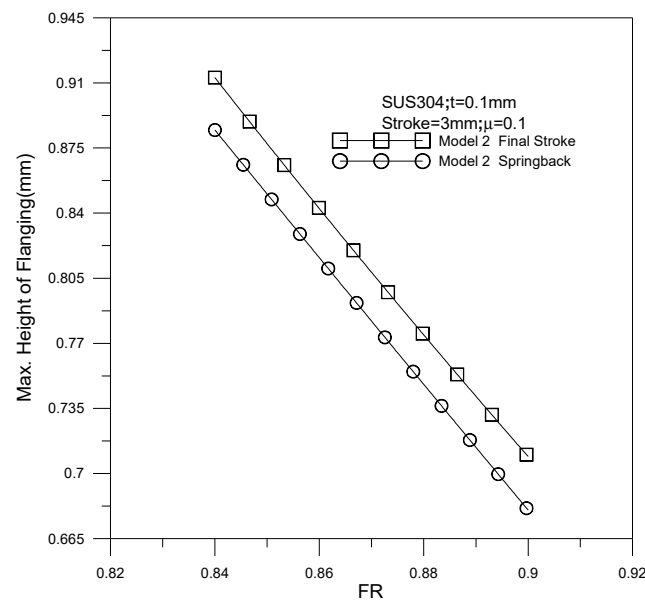

(b)

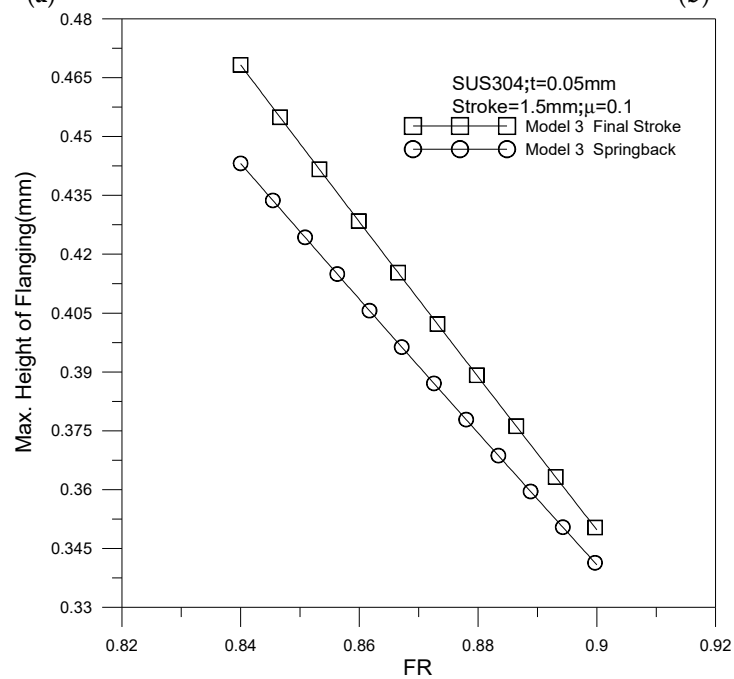

(c)

Figure 17. The relationship between the forming ratio and the maximum height of the flange: (a) Model 1; (b) Model 2; (c) Model 3. 
Meanwhile, the results reveal that the average values of maximum dimension of the hole for Model 1 varies of $B r, R_{p}$, and $F R$ are 5.09, 5.095, and $5.08 \mathrm{~mm}$, respectively, as shown in Table 8, and the maximum deviation approaches $0.3 \%$. For Models 2 and 3, the maximum deviations are close to 0.04 and $0.08 \%$, respectively.

Especially as these three models of stainless steel sheets are applied to draw a flanged square hole, the minimum flange thickness and maximum dimension of the hole would not be influenced with the variations of $\mathrm{Br}, \mathrm{R}_{\mathrm{p}}$, and $F R$ shown in Table 8 . The results can be provided as the design of drawing process for a flanged square hole in thin stainless steel sheet.

\section{Conclusions}

The 3D finite element analysis program used in this study draws from finite deformation theory for an updated Lagrangian formulation of incremental elastoplastic deformation. Dynaform and the LS-DYNA analysis engine were used in the study, and scale factor correction was also carried out. A new microscopic elastoplastic material model was established and used to modify the influence of the scale effect on the thin sheets. The accuracy of this method, which involved the finite element analysis of elastoplastic deformation, was confirmed through simulation and experiments. Both were used to accurately analyze the complete stretch forming process of a flanged square hole in thin stainless steel. The results of square hole-flange processes are concluded below.

1. The punch load increased with an increase in the radius of the fillet of the square hole $(\mathrm{Br})$, caused by an increase in the area of contact between the punch and the sheet.

2. The maximum principal stress/strain and height of the flange increased with an increase in the value of $\mathrm{Br}$ due to the larger induces' higher internal force in the material during forming.

3. The load on the punch decreased with an increase in punch fillet radius $\left(R_{p}\right)$, because the sliding between the punch and the material that occurs during the forming stroke takes place over a greater distance.

4. The maximum principal stress in Model 1 did not change very much with a change in punch fillet radius. However, for the other two models, the maximum principal stress decreased with an increase in the punch fillet radius due to the larger $R_{p}$ value reducing the load and the stress during forming.

5. The maximum principal strain also decreases very slightly with an increase in the punch fillet radius; the change in strain in Model 1 was 0.07 , and the average maximum principal strain approached 0.575 .

6. The forming ratio $(F R)$ had a significant effect on the drawing process, and when the forming limit ratio of the flange was $F L R=0.84$, cracking occurred in the corners and wrinkles were induced in the undrawn areas of the sheet.

7. The punch load decreased as the value of $F R$ increased due to the larger forming ratio results in a larger hole and the contact area between the punch and the sheet is smaller.

8. The maximum principal stress/strain and height of the flange decreased with the increase in $F R$. It is because the larger $F R$ draws less material, and the corresponding punch load is smaller.

9. Using finite element analysis, it was possible to accurately analyze the complete deformation process of flange drawing, obtain a comprehensive deformation history, and predict the forming problems that might arise during an actual drawing process.

Author Contributions: Conceptualization, T.-C.C.; methodology, T.-C.C.; software, C.-M.H.; validation, T.-C.C., C.-M.H. and C.-C.W.; formal analysis, T.-C.C. and C.-M.H.; investigation, T.-C.C. and C.-M.H.; writing-original draft preparation, T.-C.C., C.-M.H. and C.-C.W.; writing-review and editing, C.-C.W.; visualization, C.-C.W.; supervision, C.-C.W.; project administration, C.-C.W.; funding acquisition, T.-C.C. All authors have read and agreed to the published version of the manuscript. 
Funding: This research was funded by Ministry of Science and Technology in Taiwan, grant numbers MOST 109-2221-E-167-007, 110-2221-E-167-019, 110-2622-E-167-008.

Conflicts of Interest: The authors declare no conflict of interest.

\section{References}

1. Aminzahed, I.; Mashhadi, M.M.; Sereshk, M.R.V. Investigation of holder pressure and size effects in micro deep drawing of rectangular work pieces driven by piezoelectric actuator. Mater. Sci. Eng. C Mater. Biol. 2017, 71, 685-689. [CrossRef] [PubMed]

2. Chen, T.C.; Hsu, C.M. An analysis of stainless steel micro square hole-flange using drawing processes. Key Eng. Mater. 2015, 626, 402-407. [CrossRef]

3. Phanitwong, W.; Thipprakmas, S. Multi draw radius die design for increases in limiting drawing ratio. Metals 2020, 10, 870. [CrossRef]

4. Bouchaâla, K.; Ghanameh, M.F.; Faqir, M.; Mada, M.; Essadiqi, E.H. Numerical investigation of the effect of punch corner radius and die shoulder radius on the flange earrings for AA1050 and AA1100 aluminum alloys in cylindrical deep drawing process. Heliyon 2021, 7, e06662. [CrossRef] [PubMed]

5. $\quad$ Su, K.F.; Chen, H.C.; Lin, H.R. Stamping Guidance; Chuan-Hwa: Taipei, Taiwan, 1991.

6. $\quad$ Dai, Y.J.; Hsu, Y.T. Press Processing and Die Design; Tung-Chiao: Taipei, Taiwan, 1981.

7. Kawka, M.; Makinouchi, A. Shell-element formulation in the static explicit FEM code for the simulation of sheet stamping. J. Mater. Process. Technol. 1995, 50, 105-115. [CrossRef]

8. Leu, D.K. Finite-element simulation of hole-flanging process of circular sheets of anisotropic materials. Int. J. Mech. Sci. 1996, 38, 917-933. [CrossRef]

9. Takuda, H.; Hatta, N. Numerical analysis of formability of a commercially pure zirconium sheet in some sheet forming processes. Mater. Sci. Eng. 1998, 242, 15-21. [CrossRef]

10. Kumagai, T.; Saiki, H.; Meng, Y. Hole-flanging with ironing of two-ply thick sheet metal. J. Mater. Process. Technol. 1999, 89, 51-57. [CrossRef]

11. Worswick, M.J.; Finn, M.J. The numerical simulation of stretch flange forming. Int. J. Plast. 2000, 16, 701-720. [CrossRef]

12. Huang, Y.M.; Chien, K.H. Influence of the punch profile the limitation of formability in the hole-flange process. J. Mater. Process. Technol. 2001, 113, 720-724. [CrossRef]

13. Leu, D.K.; Chen, T.C.; Huang, Y.M. Influence of punch shapes on collar-drawing process of sheet steel. J. Mater. Process. Technol. 1999, 88, 134-146. [CrossRef]

14. McMeeking, R.M.; Rice, J.R. Finite-element formulations for problems of large elastic-plastic deformation. Int. J. Solids Struct. 1975, 11, 601-616. [CrossRef]

15. Hinton, E.; Owen, D.R. Finite Element Software for Plates and Shell; Pineridge Press: Swansea, UK, 1984.

16. Hughes, T.J.R. The Finite Element Method; Prentice-Hall: Englewood Cliffs, NJ, USA, 1987.

17. Hughes, T.J.R. Generalization of selective integration procedures to anisotropic and nonlinear media. Int. J. Numer. Methods Eng. 1980, 15, 1413-1418. [CrossRef]

18. Swift, H.W. Plastic instability under plane stress. J. Mech. Phys. Solids 1952, 1, 1-18. [CrossRef]

19. Peng, L.; Liu, F.; Ni, J.; Lai, X. Size effects in thin sheet metal forming and its elastic-plastic constitutive model. Mater. Des. 2007, 28, 1731-1736. [CrossRef]

20. Liu, F. Study on the Key Technology of Micro-Forming Process. Ph.D. Thesis, Shanghai Jiao Tong University, Shanghai, China, 2006.

21. Oden, J.T.; Pries, E.B. Nonlocal and nonlinear friction laws and variational principles for contact problems in elasticity. ASME J. Appl. Mech. 1983, 50, 67-76. [CrossRef]

22. Saran, M.J.; Wagoner, R.H. Consistent implicit formulation for nonlinear finite element modeling with contact and friction. Part, I. Theory. ASME J. Appl. Mech. 1991, 58, 499-506. [CrossRef] 